Article

\title{
A Cultural Heritage Framework for Preserving Qatari Vernacular Domestic Architecture
}

\author{
Asmaa AL-Mohannadi, Raffaello Furlan * ${ }^{\mathbb{D}}$ and Mark David Major \\ College of Engineering, Qatar University, Doha 2713, Qatar; a.al-mohannadi@qu.edu.qa (A.A.-M.); \\ m.major@qu.edu.qa (M.D.M.) \\ * Correspondence: raffur@gmail.com
}

Received: 30 June 2020; Accepted: 31 July 2020; Published: 6 September 2020

\begin{abstract}
Architecture and urbanism in the Arabian Gulf region, and specifically in the State of Qatar, offer many scenes to observe the loss of urban identity and cultural heritage in the various components of the built environment, including residential architecture. Many people attribute this to rapid development in globalization and the adoption of Western standardization in planning and design practice. Conversely, in the field of architectural sociology, scholars argue that socio-cultural factors such as privacy, gender segregation, and hospitality are the important variables for determining the spatial form of Islamic residential architecture. This research study aims to investigate the degree to which the shaping of the spatial form in a sample of Qatari vernacular courtyard houses embeds socio-cultural factors based on morphological analysis of human behavior and activities in domestic space. The study utilizes space syntax analysis to explore the spatial connectivity of four Qatari vernacular courtyard houses related to domestic functions as a realization of inhabitants' system of activities and a manifestation of culture as a way of life. The study's findings shed light on the spatial formation of Qatari vernacular courtyard houses as a realization of socio-cultural imperatives, thus reflecting the essence of societal formation in the domestic architecture of old Qatari settlements. The insights from this research study can help to contribute to a cultural heritage-framework for the preservation of distinctive Qatari Vernacular Residential Architecture based on the analytical criteria of housing spatial form, socio-cultural factors, and the interrelation between both.
\end{abstract}

Keywords: architectural identity; courtyard; cultural heritage; domestic space; house form; space syntax

\section{Introduction}

In a globalized world, architectural identity becomes a fundamental question about a society's culture as a way of life as realized in its built environments. The issue revolves around the ability of architecture to convey meaning and serve as a valuable reference to any defined community undergoing urban and socio-cultural transformations. The built environment of the Middle East North Africa (MENA) region and the Arabian Gulf cities are evolving, and so does the socio-cultural values of people who live there. There is an acute awareness about the loss of cultural identity in the built environment, which many people consider a rising urban threat affecting the regional architecture. Many scholars advocate for a cultural heritage approach to the preservation of the distinctive Qatari Vernacular Residential Architecture as a means of mirroring a resilient connection between populations and culture as a way of life [1-3].

There appears to be a direct correlation between built form and the socio-cultural context in domestic Islamic architecture. Traditional domestic architectural typologies such a courtyard houses in the MENA region and Arabian Gulf demonstrate a clear relationship between socio-cultural variables such as privacy, gender segregation, and hospitality [4-8]. It is well-established that 
the influence of socio-cultural factors on domestic form and space can serve as a substantive manifestation of architecture's ability to provide a societal identity across different regions and eras [9-11]. In this sense, residential architecture is a valuable cultural heritage resource worthy of preservation for future generations.

This paper addresses a gap in our knowledge about the manifestation socio-cultural variables in the spatial form of Qatari vernacular courtyard-houses and the need to define better a cultural heritage framework for the preservation of the distinctive Qatari vernacular residential architecture. The paper deploys space syntax analysis of visual connectivity as realized in the domestic space of four Qatari vernacular courtyard-houses, and the inter-relationship to inhabitants' activities as a manifestation of culture as a way of life in these houses, to address this gap in our knowledge. We support this analysis by reviewing photographic documentation, technical reports, and the compiling of other architectural material and cultural resources available in the historical record. The insights of the study can help to define a cultural heritage framework for the preservation of distinctive Qatari vernacular residential architecture based on objective criteria about house form and space, the socio-cultural variables embedded within the physical object such as privacy, gender roles, and hospitality, and the system of domestic activities in vernacular space. Such a framework can help to advocate for the preservation of architectural identity in the residential built environments of the State of Qatar and the broader MENA/Arabian Gulf region.

\section{Literature Review}

\subsection{A Cultural Heritage Approach to Preserve Urban-Architectural Identity}

Architecture and urbanism in many Islamic-MENA countries are useful scenes to observe the loss of urban identity and cultural heritage both as a consequence of instability and massive-scale destruction [12,13], or as a drawback of globalization and rapid urbanization. The first case is relatable to urbanism in countries like Syria, Iraq, and Palestine, and the latter is the case of oil-producing Gulf countries such as the UAE, Kuwait, and the State of Qatar as the focused scope of analysis in this research paper. Thus, the loss of identity in the built environment is rising an urban challenge to the sustainable development process that advocates for social and cultural sustainability besides its economic motives. In the broader regional context, the loss of urban and architectural identity is discernible in the various components of the built environment, including residential architecture and places of dwelling.

For us to understand this loss of architectural identity, it is necessary to trace the history of urbanism in the region. Socio-cultural and tribal traits governed the architecture of the primitive societies in many Gulf cities, clearly following Islamic principles in building for establishing the public and private realms. The result was compacted neighborhoods that resembled communal and social values, notwithstanding the limits of finances, building material, and construction techniques and know-how [14-16].

Meanwhile, Western planners aided by state ambitions introduced a form of urbanism to the region geared towards fast urban development since the discovery of oil and the wealth generated in the mid-1900s (Figure 1). Adham [17] explains that Doha's most noticeable urban transformation took place in the 1950s-1990s, in which modernization and foreign consultation overtook the planning practice. Therefore, the alienation of the traditionally harmonized urban settlements resulted in the inadequate integration of the urban fabric both physically and socio-culturally. Worse was the decision to demolish valuable vernacular structures or early-modern buildings during this transitional period of urbanism, leading to a significant loss of vernacular architectural heritage. Such demolition decisions were either part of land acquisition to establish infrastructural projects or due to the expansion of developments in traditional neighborhoods $[18,19]$. 


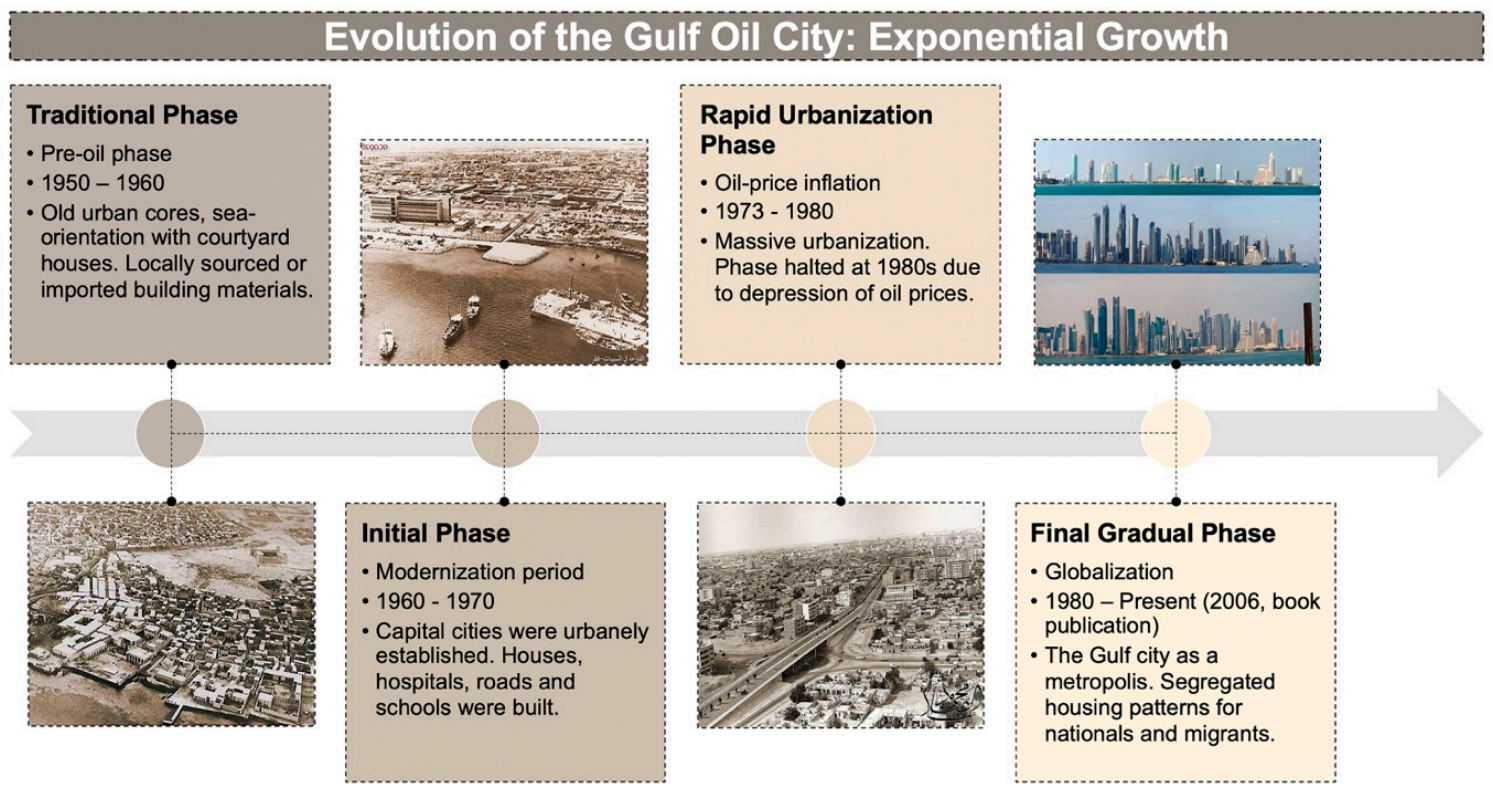

Figure 1. Evolution of Doha as a Gulf City [14] summarized by the Authors.

Historic preservation efforts highly value the enhancement of the traditional urban fabric to avoid the long-term loss of significant vernacular architectural heritage. The built environment of historic urban landscapes is necessary to sustain the socio-cultural heritage of a community or society. In this prospect, the International Council on Monuments and Cities (ICOMOS) explains cultural heritage as the "expression of the ways of living developed by a community and passed on from generation to generation" [20]. Much of the global debate on cultural heritage targets the conservation and sustainable management of heritage sites, where world-class organizations and NGOs play an advocacy role in the process [21,22].

Projecting the broad concept of cultural heritage into the MENA region triggers a highly intensified debate into the vital cultural assets of the Arab heritage and the rapidly evolving socio-economic dynamics of the region [23]. The conservation of cultural heritage extends beyond the physical features to include the socio-cultural characteristics of the Arab society that are still part of everyday life. According to Hassan, Trafford, and Youssef [24], conservation of cultural heritage must consider the socio-cultural dynamics and the economic wellbeing of the communities, including the daily life rituals and activities specific to the socio-cultural setting. Such intangible cultural heritage assets include festivals, songs, literature, and the 'flesh and blood' of urban heritage [24].

Referring to the State of Qatar, its National Development Framework 2032 describes the principles for sustainable living in the 21st century. The emphasis of the spatial framework is to achieve compactness of city growth through traditional neighborhood development, livability, and cultural heritage. The development framework is strategized in qualitative and quantitative improvements of the city districts through utilizing energy efficiency and the most recent best practices in urban design and architecture, meanwhile conserving Qatar's historical and cultural heritage [25]. This paper, therefore, attempts to define a cultural heritage approach for the preservation of the distinctive Qatari vernacular residential architecture in light of QNDF 2032 and Qatar National Vision 2030.

\subsection{A Cultural Heritage Approach for Domestic Architecture}

Regarding residential architecture, the upgrade from socially coherent courtyard houses in compacted walkable neighborhoods to modern multi-story villas in sprawling cities marks an interesting urban phenomenon not only in Qatar but also in many other Arabian and Islamic countries. In the past, the courtyard house was a widely spreading domestic typology across different climates and cultures in the world. Its form supports family and community life and proves its usefulness and popularity as 
a socially sustainable facet of architecture in traditional and historical settlements, especially in the MENA region $[4,5,7,16]$. Moreover, traditional houses are governed by Islamic and societal principles that attribute to their form and function in response to environment-behavior interactions, leading to homogeneity and harmony in the overall urban fabric (Figure 2).

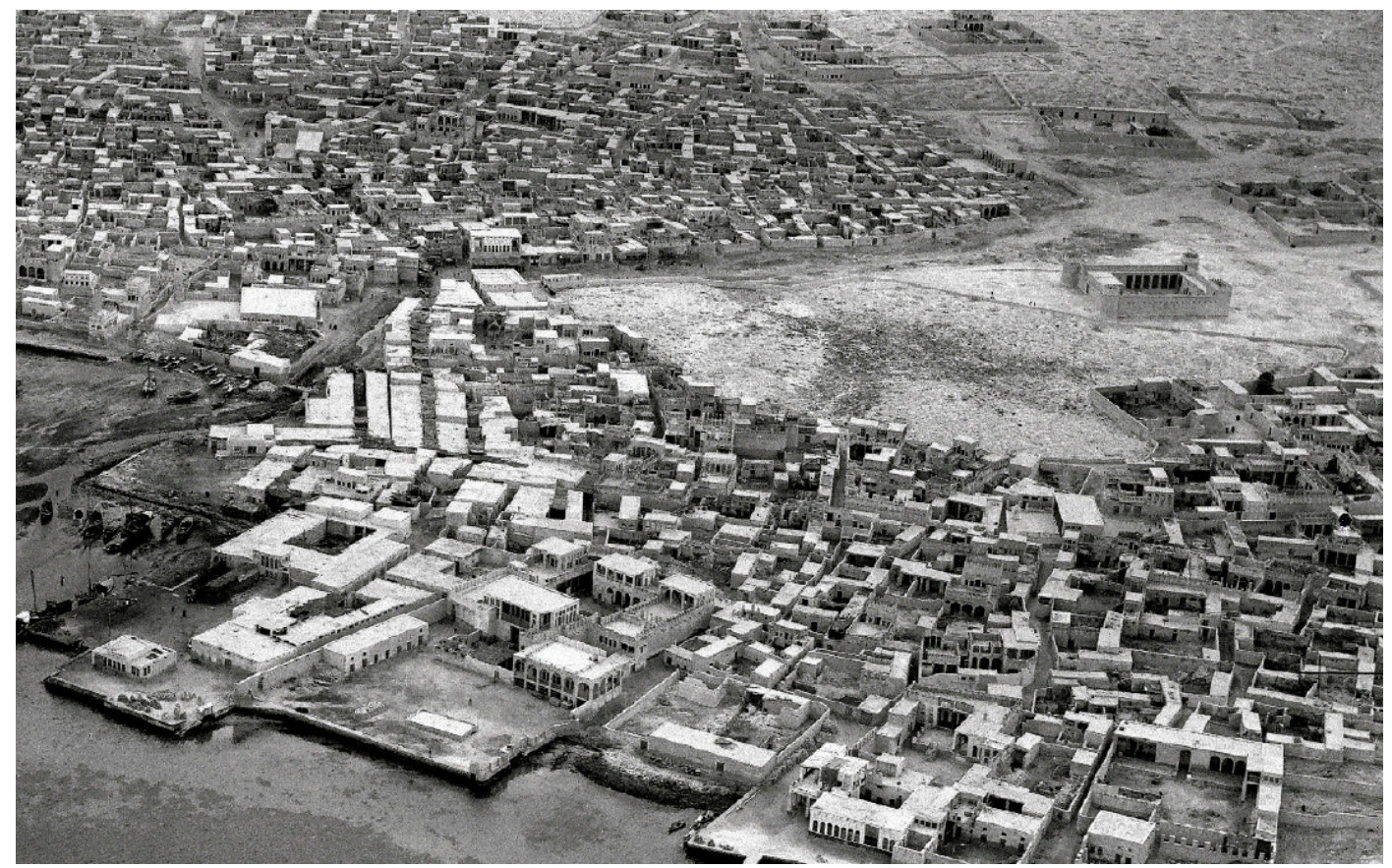

Figure 2. Characteristic urban fabric composed of courtyard houses in old Doha, Qatar [25].

Cultural heritage directly relates to residential architecture as it majorly influences the architectural form of the house and the activities within the household. In this section, we briefly review studies in Indonesia as a south Asian Muslim-majority country. Studies highlight that the traditional Acehnese house might extinct due to modernization and migration of native populations from rural areas to cities. In light of architectural resilience and adaptation, the traditional Acehnese house is effectively mitigating climatic disasters, adding further necessity to preservation of its valuable cultural heritage [26]. The reviewed studies are relatable to the courtyard house scheme that represents the architectural built heritage of Qatar and its endurance and effectiveness as a passive low-energy structure, considering the climatic conditions in the country. The challenge is related to the inability to reproduce the Qatari courtyard house scheme into modern residential architecture due to planning regulations and other design-driven imperatives.

Consequently, it is necessary to investigate further the loss of architectural identity and advocate for the preservation of cultural heritage, bearing in mind the increasing drawbacks of globalization and standardization of the housing construction industry in the current era. The contemporary construction of housing tends to reflect the requirements of a global market instead of local architectural identity and cultural heritage. The challenge today is to ensure a development process that harmonizes local requirements with enforced global imperatives and to preserve the valuable cultural heritage of the courtyard house.

\subsection{The Courtyard House: Socio-Cultural Factors in Human Activities}

The courtyard house typology is one of the oldest forms of dwelling in the Arab world. It dates back to the Graeco-Roman period, and Arabs later adopted the building typology and their collective knowledge about tensile construction. Initially, inland Arab settlements consisted of tents surrounding a common central core or space as a means of achieving security and endurance from desert climatic 
conditions [27]. Thus, the open space in the courtyard house was the result of a series of historical urban transformations responding to a set of everyday socio-cultural and environmental necessities [28-30]. The contrast of solid and void between the thick exteriors and the open interiors responds to the socio-cultural parameters of vernacular Islamic architecture as an introverted typology. According to Alkhalidi [31], the interior of the courtyard house is the focus of attention in Islamic architecture, as it symbolically represents status and identity. Meanwhile, the exterior of the courtyard house represents homogeneity, blending with the social context as a way to establish a collective identity [31].

The spatial form of the courtyard house presents privacy, gender segregation, and hospitality as influential characteristics in determining its internal configuration [32,33]. Such patterns are integral in the distinctive family lineages and the Arab cultural heritage of the Arab-Muslim society. Privacy is a leading main social and cultural parameter that affects the spatial form of courtyard houses [34]. Privacy is layered hierarchically from privacy from the neighbors' dwellings to privacy between family members within the household [35]. Islamic culture appreciates the individual's right to have a privatized space and supports the maintenance of personal privacy at home, leading to layered levels of privacy prioritizing the privacy of the individual, family, and female guests followed by male guests and then outsiders (Figure 3).

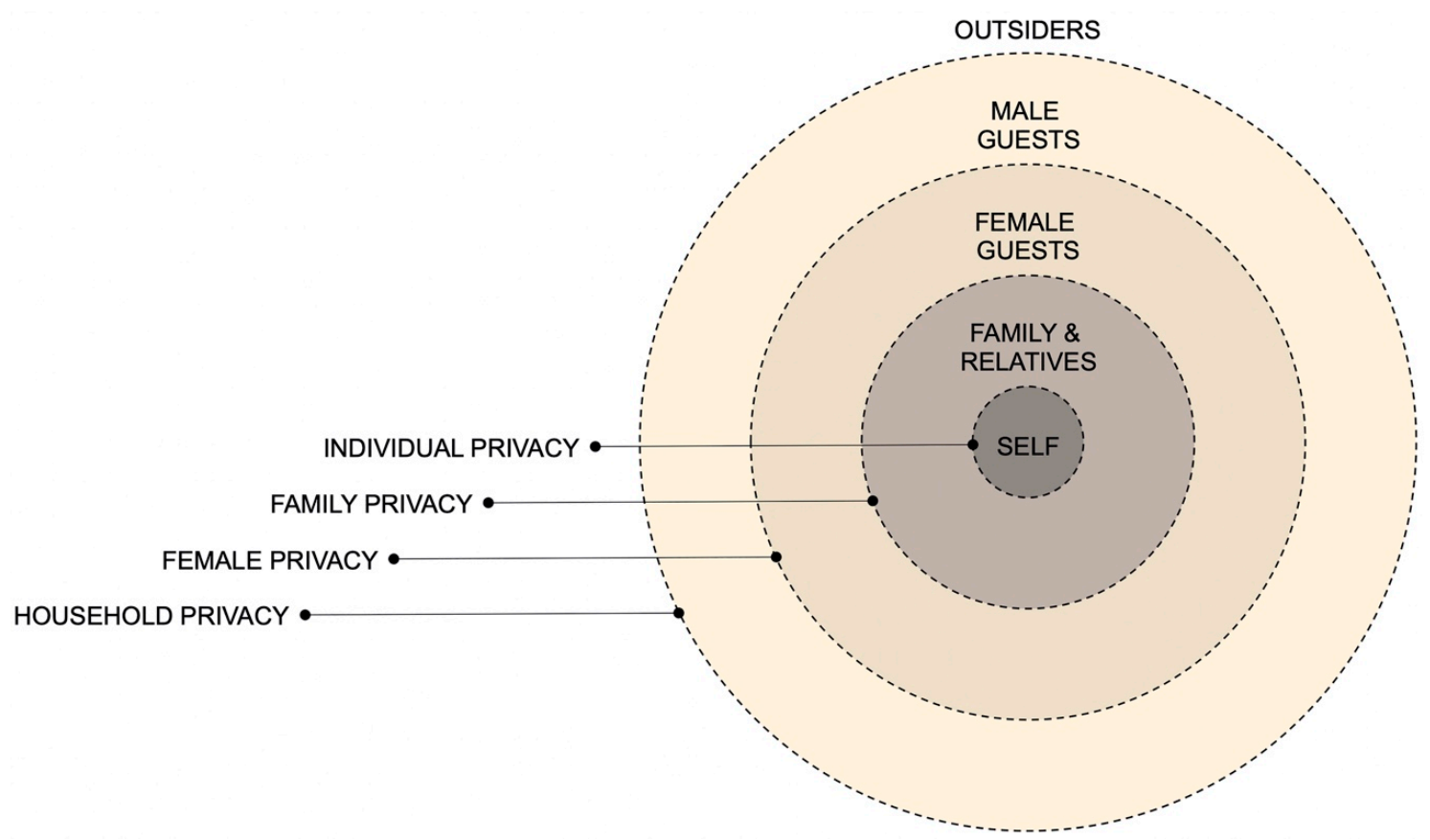

Figure 3. Privacy in traditional Muslim homes [35,36].

One outcome of privacy is gendered spatial segregation, which in itself is a highly influential pattern in the spatial form of Muslim houses [37]. The level of gender segregation tends to vary between cities in the MENA region, as it has been subject to different interpretations of religious norms, economic conditions, specific socio-cultural circumstances, and identity guidelines. Such differences enriched the urban history of Muslim cities, as seen through the variety of courtyard house models and design forms of domestic spaces, subjecting architecture to local imperatives [38-40].

Consequently, hospitality was a fundamental trait of the Arab culture in pre-Islamic Arabia. Islam further approved it as an ethical value and a unifying attribute in the Muslim community [27,41]. Embracing the socio-cultural characteristic of hospitality gives rise to the Majlis space in the early primitive tents and the traditional courtyard houses. Majlis spaces appear in most contemporary houses as well, indicating that hospitality is still an active practice of the culture. Meanwhile, Sharon Nagy [42] explains that the essential cultural traits of earlier societies as hospitality and generosity are recently "weakening with miscegenation and materialism" [42] (p. 131). This argument sheds light on the 
inadaptability of contemporary dwellings to cultural heritage, raising fundamental concerns on socio-cultural sustainability of present-day residential architecture.

In terms of human activities, the courtyard house presents common socio-behavioral phenomena with a response to its formative scheme and architectural configuration, such as privacy, personal space, and territoriality [43]. Most domestic activities take place within the protected core of the courtyard, which is surrounded by small rooms and enclosed spaces preserved for private family uses. Bekleyen and Dalkil [44] clarify that the courtyard houses of the hot-arid regions establish strict territoriality as a human-behavior phenomenon. It includes the privatization of space created for introversion and separation of public and private functions [44] (p. 908).

Regarding vernacular courtyard houses in Qatar, Sayigh, and Marafia [45] conducted a study in the late 1990s to quantify and analyze the vernacular architecture of Qatar. They referred to the indigenous passive techniques used in courtyard houses to restore thermal comfort as a means to climatically mitigate for heat during summer days [45] (p. 26). Such techniques relate to spatial form and physical layout of the buildings. In the past, courtyard houses within compact neighborhoods shared thick mud walls resulting in mutual shade and improved thermal comfort within the interior space (Figure 4). The interior space, however, surrounded an open-air courtyard that resembled the core of the housing unit, both physically and socially [46-48].

The intermediate spaces surrounding the courtyard are important in the analysis of vernacular courtyard houses in Qatar. Among the most valuable architectural elements that presents in discussion of the courtyard typology is the iwan. According to Petruccioli [4], iwan is a Persian term that translates into liwan in Arabic, which best describes a space closed by walls on three sides and open on the fourth side. It is usually vaulted and arched while it opens into a courtyard or hall from one side. Thus, Qatari people refer to the iwan as "liwan" in the local dialect, proving that the iwan is a widely spreading architectural form not only in Islamic architecture, but also in Parthian and Sassanid architecture [49]. The origin of the iwan might raise a debate over its evolutionary process and whether it originally evolved as a local product or was imported as a universal model $[4,49]$.

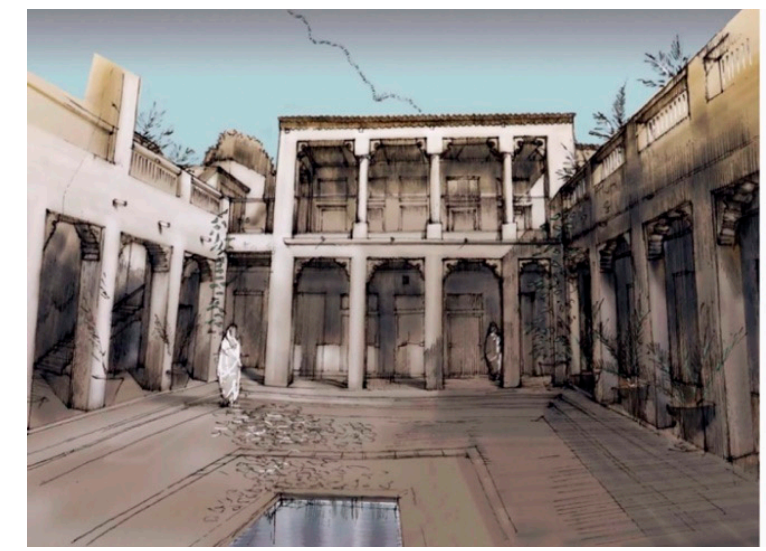

(a)

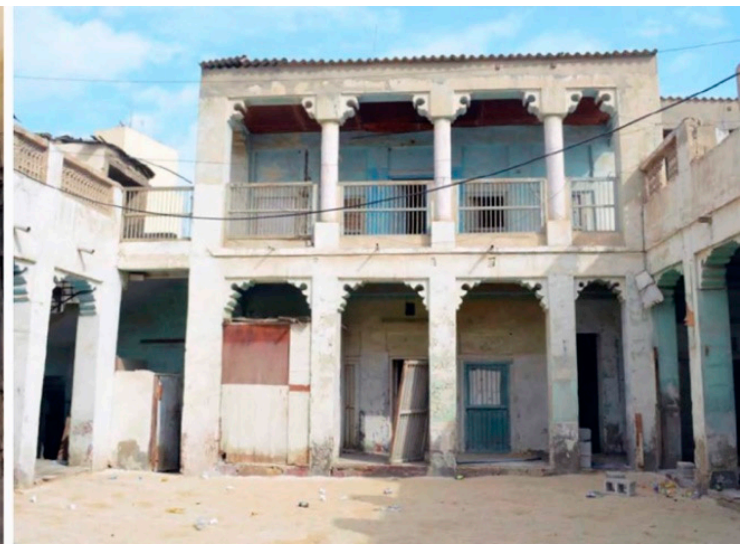

(b)

Figure 4. Old house in Al-Asmakh zone, rendered (a) and the recent situation (b) [50].

Based on the previous discussion of the three socio-cultural factors of privacy, gender segregation, and hospitality in the Arab and Gulf regions, similar manifestations are observable in the social context of Qatar. Qatar is a traditional Muslim country and is a gender-divided society. The spatial form of the Qatari vernacular courtyard house interrelates to social patterns of privacy and gender segregation in precise ways in terms of entries, courtyard ratio and form, location and arrangement of spaces and rooms, proxemics and other spatial configurations [51]. In terms of hospitality, it is the spatial existence of preserved areas for visitors and invitees within the household, which are common in the Qatari courtyard house. Majlis units were not large in the past. Instead, they were small, secured, 
and humble spaces, modestly decorated to present generosity of the household owners and provide visitors with adequate space within the existing formal and financial limits [27,34].

In terms of activities within the courtyard house, we refer to the archeological references that studied physical evidence of the material culture of old Qatar. In her recent archeological study about Islamic archaeology in Qatar, Hicks [52] presents activities within residential houses of Qatar based on evidence dating back to the 18th century through to the early 20th century. The study sheds light on the activities of women within domestic compounds at three key sites in Northern Qatar. Such activities relate to evidence for ephemeral courtyard structures and midden material as spaces used by women to cook, prepare food, socialize, and perform other domestic activities [52].

Socio-cultural background and environment-behavior activities relate significantly to the formation and spatial arrangement of the typical traditional Qatari household of the courtyard typology, where archeological remains signify the vital linkage between the spatial formation of traditional settlements and socio-cultural aspects of the society. Archeological remains also provide a valuable reference to the nature of activities performed in the courtyard house and the effect of the architectural scheme on the behavioral aspect of dwellers and inhabitants. Besides preserving the vernacular domestic architecture of Qatar through archeological and architectural conservation/preservation, it is significant to protect the valuable cultural heritage and intangible resources of the old Qatari society, specifically those related to the activities associated with the courtyard housing scheme.

\subsection{Spatial Form and Culture as a Way of Life}

The disciplinary context of this paper revolves around the spatial form of the house and culture, which is intensively theorized by Amos Rapoport [9]. Rapoport establishes the correlation between spatial form and the influence of culture and human activities on architecture. He further explains the construction of a society based on a collective agreement that defines its tradition approved by time, activity, and public consensus. He argues that when society abandons a traditional form, it will eventually disappear due to the collective social power of acceptance and rejection. Rapoport $[9,53]$ defines the act of building a house as the creation of a social unit of space to prove that house form is a consequence of socio-cultural and physical factors. He argues it is valid to state that the relationship between house and culture is direct and holistic considering the dynamic socio-cultural background and the immediate effect of socio-cultural patterns on house form and configuration. Rapoport and Kent [54] also theorize the system of activities related to the spatial arrangement of the house as means to express the lifestyle of occupants, therefore the aggregated culture [55]. The system of activities branches into six sub-components concerning time, people, and setting. We can summarize the system of activities and sub-components as reviewed in the literature (Figure 5).

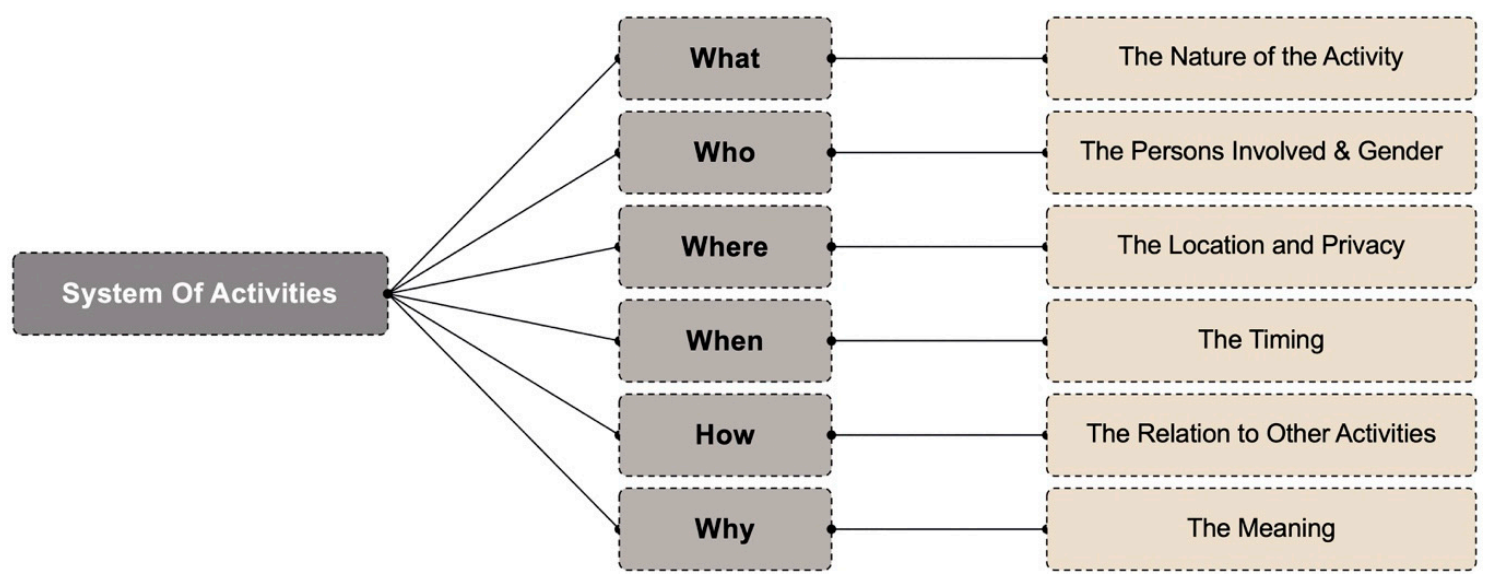

Figure 5. System of activities in relation to a housing spatial form $[54,55]$. 
Following the discussion of the spatial form and cultural lifestyle, it is necessary to refer to the basic essence of the discipline considering the relationship between people and places. Among the timeless contributions to the analysis of place as the setting of environment-behavior experience is the book Place and Placelessness by Edward T. Relph [56]. Relph argues that place is a naïve and variable expression of geographical experience. Major components utter the expression of place including (i) the idea of location in site and situation, (ii) nature and culture, (iii) circulation and spatial interaction, (iv) localization, (v) historical component, and (vi) meaning. Moreover, the nature of culture and spatial interaction are amongst the determinants of a place, proving that a place is a source of collective identity urging people and communities to develop place attachment. In Relph's theory, the formation of place consists of the physical setting, activities, and meanings. Human activities are essential in giving a place its meaning within a specific environmental context from a human-environmental point of view [56,57]. The purpose of restating such theories is to provide the proper disciplinary framework to understand how socio-cultural factors manifest themselves in the spatial form of Qatari vernacular courtyard houses. The aim is to define a cultural heritage approach for the preservation of the distinctive Qatari vernacular residential architecture through analytical methodologies and simulation, which we discuss in the following section.

\section{Materials and Methods}

\subsection{Scope of the Investigation}

The study aimed to investigate the extent to which the spatial form and distribution of Qatari vernacular courtyard houses embedded three predefined socio-cultural factors. It does so by analyzing the spatial form in a small sample of courtyard houses to identify with the three socio-cultural factors in reference to human activities. Thus, the investigation aligns with the analysis of human behavior or activities within traditional courtyard houses. Since human activities are expressions of culture as a way of life, the spatial form of vernacular houses expresses culture simultaneously. The research paper presents four selected vernacular courtyard houses and analyses them in terms of (i) spatial arrangement, (ii) predefined socio-cultural factors, and (iii) human activities (system of activities).

\subsection{Procedure Adopted to Answer the Research Question}

\subsubsection{Literature Review}

The authors referred to vernacular house plans archived in books that are both primary and secondary sources to cover the historical analysis [58-60]. The authors also approached governmental authorities working in the architectural conservation sector, such as Qatar Museums, the Ministry of Culture and Sports, and the Private Engineering Office to document old housing plans and detailed architectural drawings. All of the vernacular housing plans appear in The History of Qatari Architecture 1800-1950 [51], which is one of the few references archiving and documenting traditional Qatari vernacular architecture.

With reference to the literature review of this paper, the authors explored the selected houses based on a cumulative approach, using common knowledge about traditional architecture in the State of Qatar and Gulf region to understand the spatial configuration of these vernacular houses and further analyze the effect of socio-cultural aspects on the process of house formation. Amongst the most useful theoretical references are academic papers and proceedings exploring socio-cultural patterns in the Arab Gulf homes [34,36,61], chronological exploration of housing typologies in the Arabian Gulf $[14,62,63]$, and recent comparative assessments of vernacular and modern Qatari houses [8,32,33].

\subsubsection{Applied Methodology: Space Syntax}

The research deploys space syntax methodology as a supportive analytical tool to quantify spatial patterns in houses (see Appendix A for more detailed information about space syntax representations 
and measurements). Space syntax is a well-established methodology and tool available as interactive computer software programs to provide an objective description and analysis of spatial configuration in floor layouts, including houses and residential buildings [64-68]. The paper utilizes the standard space syntax software program (Depthmap0.5x) to analyze the pattern of visual connectivity and integration. The outcome was a series of visibility graph analysis diagrams (VGA) that uses color-coding, where red indicates the highest connectivity/integration. In contrast, blue means the least connected/most segregated (see Appendix A for more information about VGA).

\subsubsection{Methods of Data Collection (Oral and Visual Data)}

We collected general historical knowledge through oral and visual data, including attendance at seminars and architectural talks about traditional architecture in Qatar, such as the seminars featuring Eng. Ibrahim Jaidah, Eng. Mohammed Ali Abdulla, and the 2010 Aga Khan Awards for Architecture in Doha (Figure 6). These seminars and talks provided a first-hand approach to detailed information on the aspirations and challenges of the historical urban development of the city of Doha and glimpses of urbanism before the discovery of oil. The Department of Architecture and Urban Planning, College of Engineering at Qatar University organized most of these lectures through a collaborative academic seminar series.
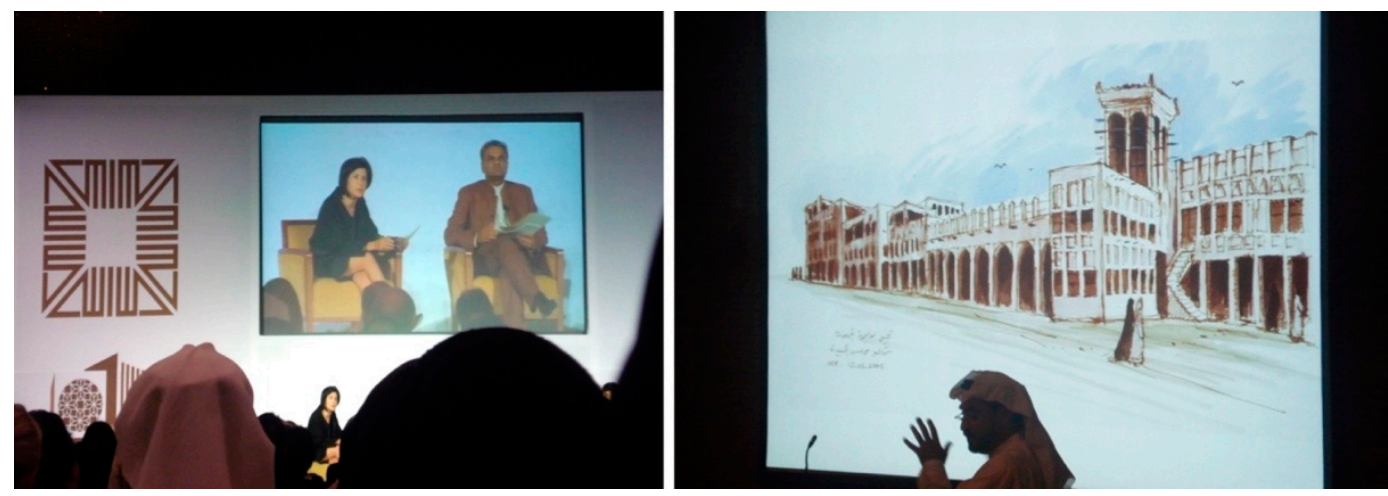

Figure 6. Seminars and academic lectures as sources of architectural data based on the oral tradition [33].

In terms of visual data, the authors re-drew the courtyard houses from the reports and surveys of old buildings by the former National Supreme Council for Culture and Arts in Qatar (currently known as the Ministry of Sports and Culture) in addition to other consultant collaborators [50,69]. The drawings focused on the courtyard scale and connection to the various spaces in each house. The selection of the courtyard houses involved several criteria, including the availability and clarity of floor plans and architectural references, time of construction, location of the housing unit, and other functional and dimensional measures.

\subsubsection{Methods of Data Analysis and Findings}

Unit of Analysis: The paper presents four selected case studies of vernacular Qatari courtyard houses. Most of the vernacular houses were built during the 1930s-1940s, where the patterns of social activities and household arrangements are predictable with reference to the socio-economical background of the era (Figure 7).

Criteria for Analysis: The study analyses the courtyard houses in terms of (i) spatial form, (ii) socio-cultural factors, and (iii) human activities or system of activities. (i) Spatial form comprises the study of the public use areas mainly for daily activities and private use areas for night activities. It also covers the architectural elements such as entrances, courtyard style and ratio, room typologies, transitional and intermediate areas, and other physical aspects. Accordingly, to test and validate the influence of (ii) socio-cultural factors as criteria for analysis, namely privacy, gendered spatial segregation, and hospitality, the sample of vernacular courtyard houses were examined in terms of 
internal configuration and graphically analyzed in terms of visibility graph analysis and connectivity using space syntax as a simulative tool. In the results section of this paper, the authors present visibility graphs of the ground floor levels only while they considered the cumulative spatial analysis of first floor levels and the outdoor areas-whenever applicable - especially in the cases of Faraj Al Ansari house and Ismail Mandani house. Further, the authors established correlations between the analytical/graphical results and the socio-cultural factors to evaluate the embedment of such factors on housing spatial form. In terms of (iii) the system of activities (refer back to Figure 5), the analysis involved both the activities related to spatial arrangement for public and private use areas as well as the analysis of the relation to the three socio-cultural factors. In this way, the relationship was found to be clear and coherent.

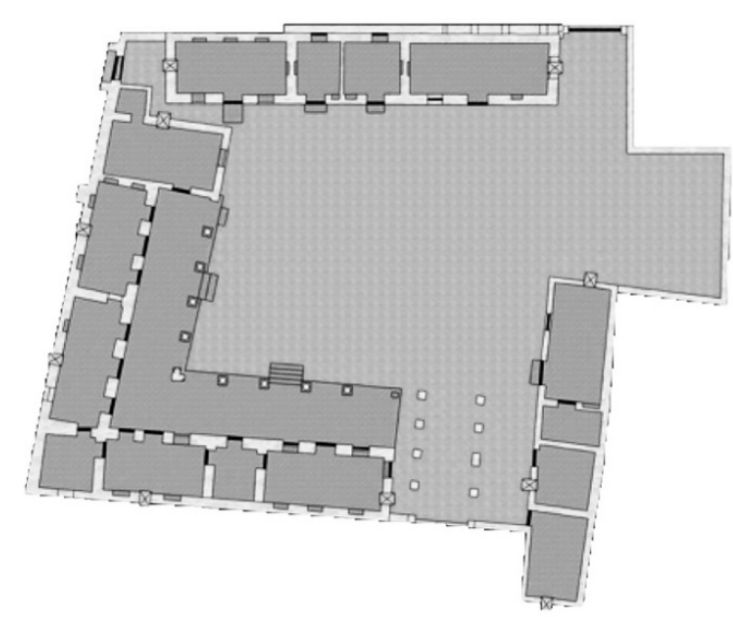

(a)

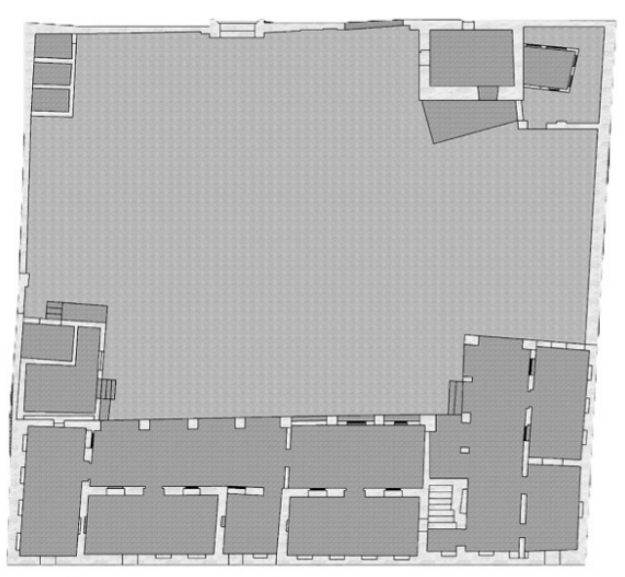

(c)

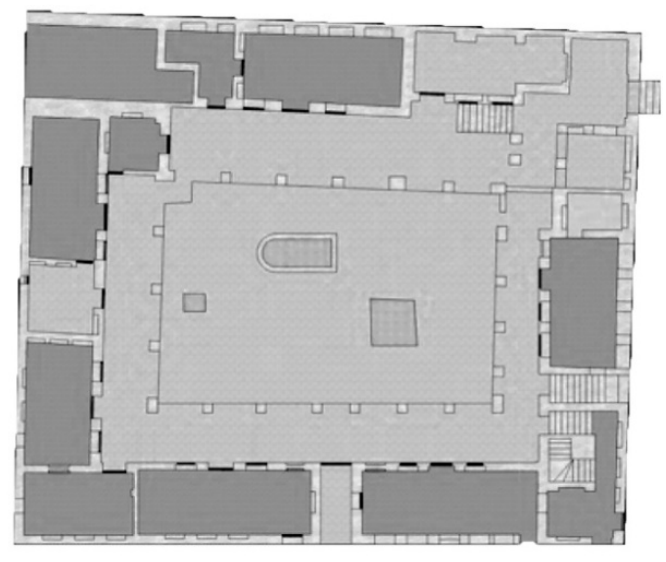

(b)

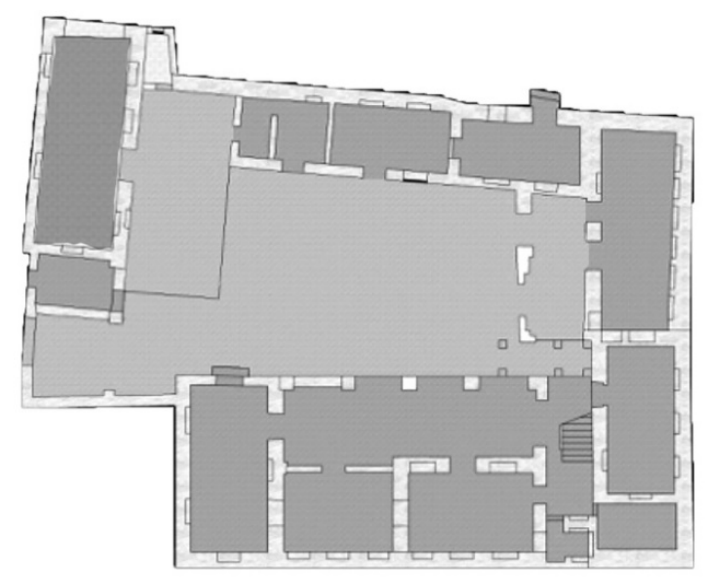

(d)

Figure 7. Floor plans of case study Qatari courtyard houses for visibility graph analysis (VGA) Analysis with courtyard indicated in light gray and rooms in dark gray by the Authors. (a) Noura Bint Saif House (b) Faraj Al Ansari House, (c) Al Jaber House, (d) Ismail Mandani House. NOTE: House plans were not set to a common scale and oriented after Jaidah and Bourennane, 2009.

\subsection{Overall Methodological Framework/Research Design}

The illustration below summarizes the Cultural Heritage Framework developed for and arising from the findings of this study (Figure 8). 


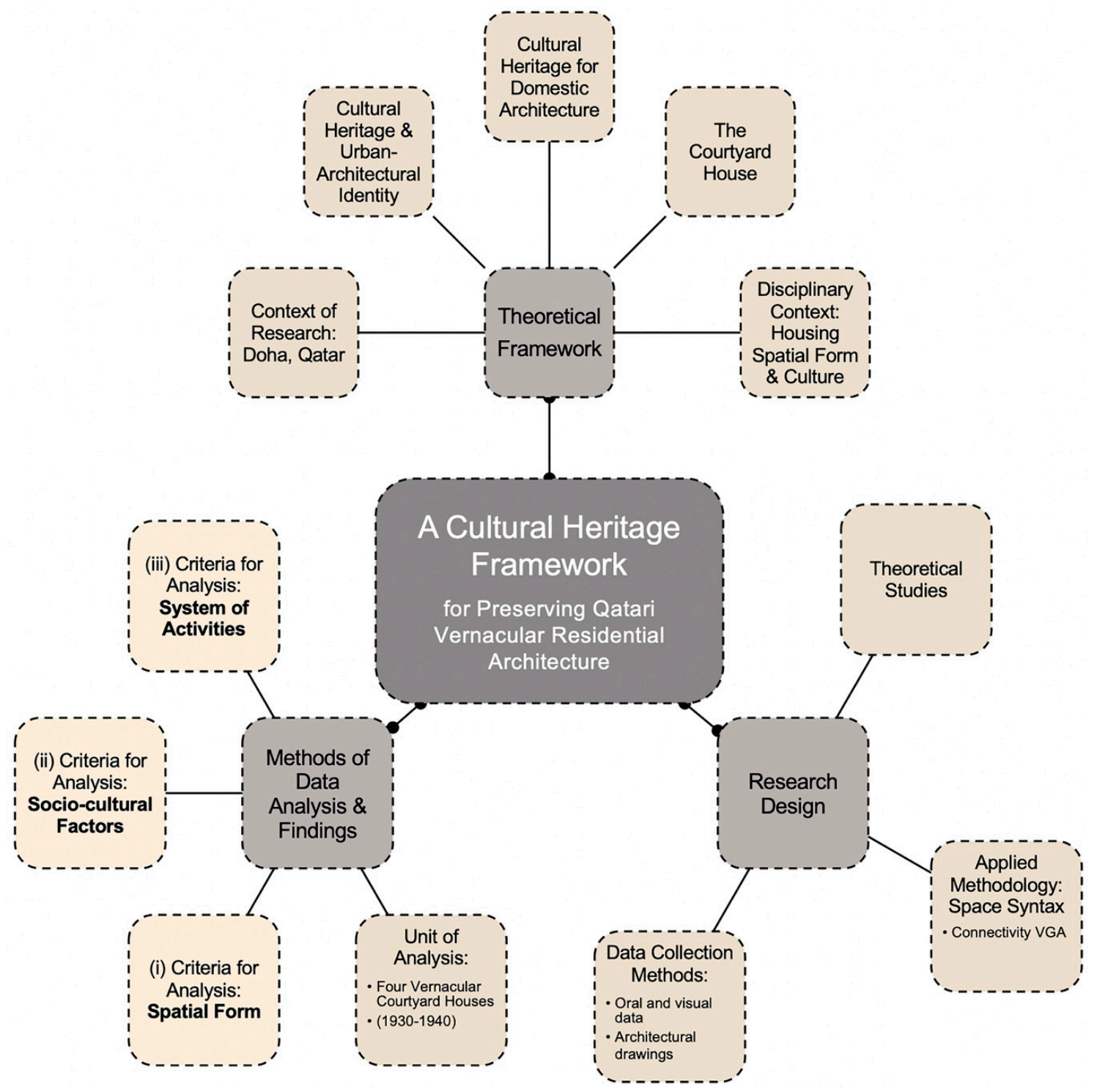

Figure 8. The Cultural Heritage Framework forming the methodological basis for this research.

\section{Results}

\subsection{Vernacular House-Case Study 1: Noura Bint Saif House|Al Asmakh, Doha|Built around 1930}

Spatial Form: (a) Public Use Spaces: The house is a single-story house with a large courtyard (Figure 9). Sand covers the courtyard grounds and consists of three main blocks, including the guest section (north side) with limited windows on both the street-facing and the courtyard-facing façade; the eastern corner (newly added section), and the main household section with seven rooms. The house is accessible from two entries: the main north gate and the northwest gate that exhibits a slight bent-entrance as a characteristic of Islamic vernacular architecture. (b) Private Use Spaces: The house has an L-shaped plan with multiple private rooms surrounded by a three-meter-wide covered porch, arcaded and decorated in simple geometric Islamic patterns. The rooms range from bedrooms, guests' bedrooms, and service areas to interior seating areas. Blocks and rooms on the southeast corner were built at a later stage. The main gate opens into the courtyard of the house while the north-west wooden gate is closer to the guest section where the Majlis is situated. It, therefore, maintains the family's privacy whenever guests access the Majlis space. 


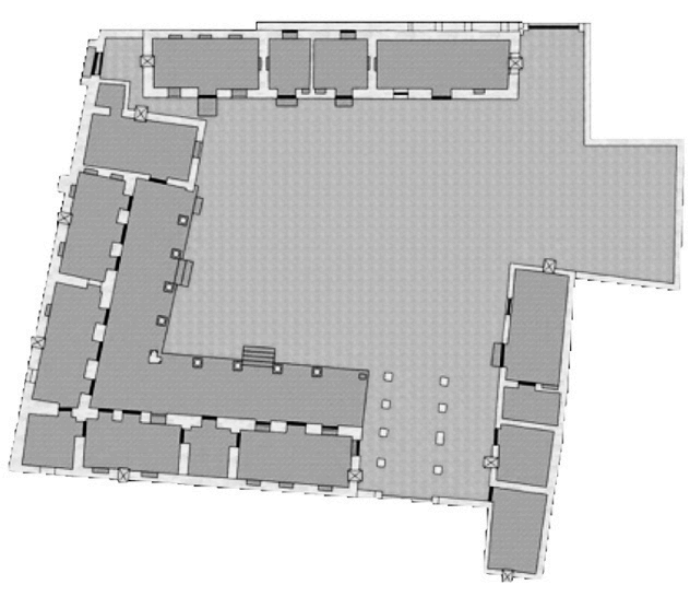

(a)

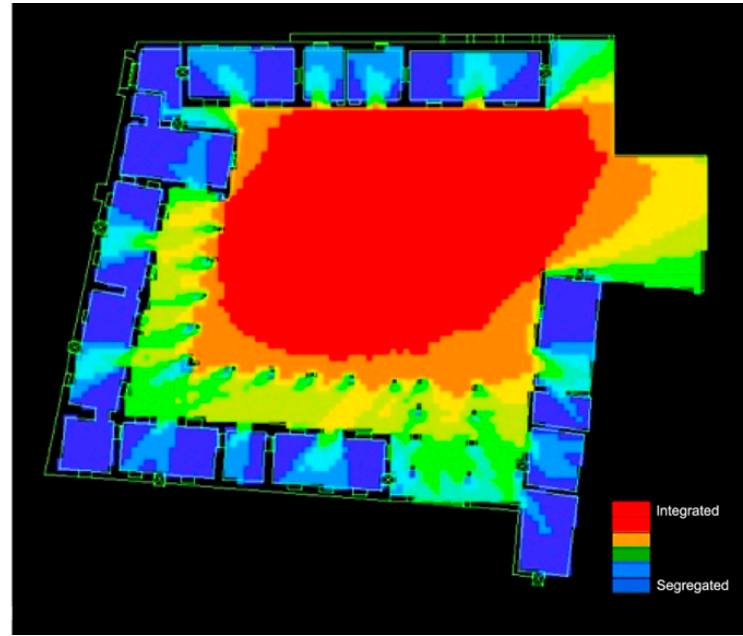

(b)

Figure 9. (a) Layout with courtyard indicated in light gray and rooms in dark gray and (b) visibility graph analysis (VGA) of Vernacular House, Case Study 1 showing integration in a range from red (integrated) through orange, yellow, green, light blue to blue (segregated) (Source: Authors).

Socio-cultural Factors: (a) Privacy: High connectivity is observed in the spacious central courtyard, signifying its low privacy. Connectivity gradually reduces around the arcades and the porch area. All the rooms within the L-shaped arrangement illustrate low connectivity, as each room only connects to the central courtyard. A related pattern to consider is the gradual yellow shades behind the columns of the porch, which indicate that behind the column, there is reduced connectivity due to visual privacy. (b) Gender Spatial Segregation: Dedicating a secured entrance to guests only, who could be male, clearly relate to the patterns of gender segregation. The areas connecting the gate to the courtyard represents a gradual connectivity pattern, where connectivity is lower by the door and increases with the approach towards the center of the courtyard. Thus, if an outsider stood by the main gate, the household would not be visually exposed, and the privacy of the family would be maintained. (c) Hospitality: The main gate on the north wall exhibits slightly higher connectivity compared to the rest of the gates and household rooms, indicating its functionality as an access point requiring lower privacy due to function. Compared to the northwest wooden entrance, the main north gate is more connected and might support the usage of the northwest wooden door as guest entry without disturbing the privacy of the family.

System of Activities: (a) Public Use Spaces: The courtyard is the setting for public use activities. The nature of activities performed in the courtyard ranges from social such as gatherings of family members or gatherings over meals due to the absence of dining rooms in the old house and the cultural norm of meeting over the three meals. Family members shared some of the meals. $m$ have their meal areas in a separate, secured space if involving more men and relatives. Most of the gatherings might occur in the intermediate spaces surrounding the courtyard, rather than in the center of the courtyard itself. Besides climatic factors such as exposure to direct sunlight, especially during the daytime, the intermediate covered porches were favored for social activities and food preparation, mostly performed by women in the morning hours. It is also valid to refer to the courtyard as a playground for the kids and the children of the family due to the sand ground cover instead of hard, paved material. (b) Private Use Spaces: All the small rooms are accessible via the porch, adding further emphasis on their private use. Some of the rooms are internally connected via small doors to ensure security and privacy of use. The guest section as well involves three rooms, indicating that in some cases, visitors could be relatives and family members of both genders, who require separation and privacy by gender. Thus, the meaning of the courtyard corresponds to its visual connectivity and spatially accessibility to the different rooms of the household, even to the secured bedrooms and personal spaces. 


\subsection{Vernacular House-Case Study 2: Faraj Al Ansari House|Msheireb, Doha|Built around 1935}

Spatial Form: (a) Public Use Spaces: The house is accessible from four entries: three from the east and one from the south (Figure 10). The main entrance is the largest eastern entry, while the other two entrances from the south lead to staircases. A large courtyard centralizes the house surrounded by a concrete porch. The architectural features of the house's façade include the typical assortment of small windows and few air-catching rectangular openings. At the same time, the roof of the interior rooms utilizes vernacular beams known as danchal [50]. (b) Private Use Spaces: The ground floor consists of nineteen rooms. The staircases that lead to the first floor are privatized for family use only. The privatized staircase that is directly accessible from the street might be used by the household owner's son and his family, reflecting an extended-family pattern and the need for spatial growth. Within the private rooms, there is an absence of windows that open to the street or the neighborhood. Meanwhile, all the private rooms directly opened into the intermediate porch space that accessed the open-air courtyard [51].

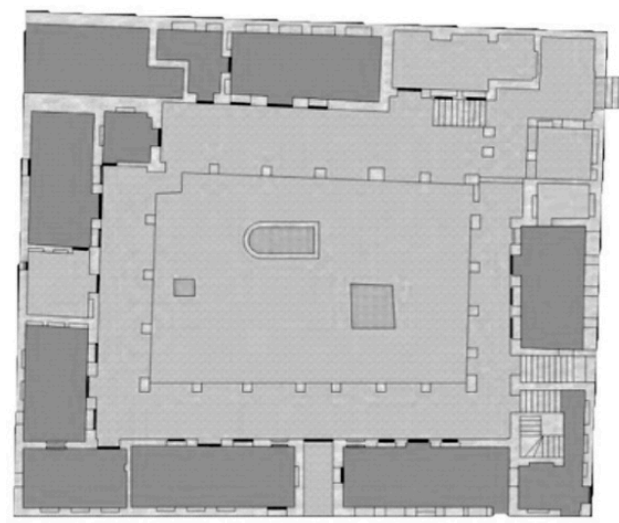

(a)

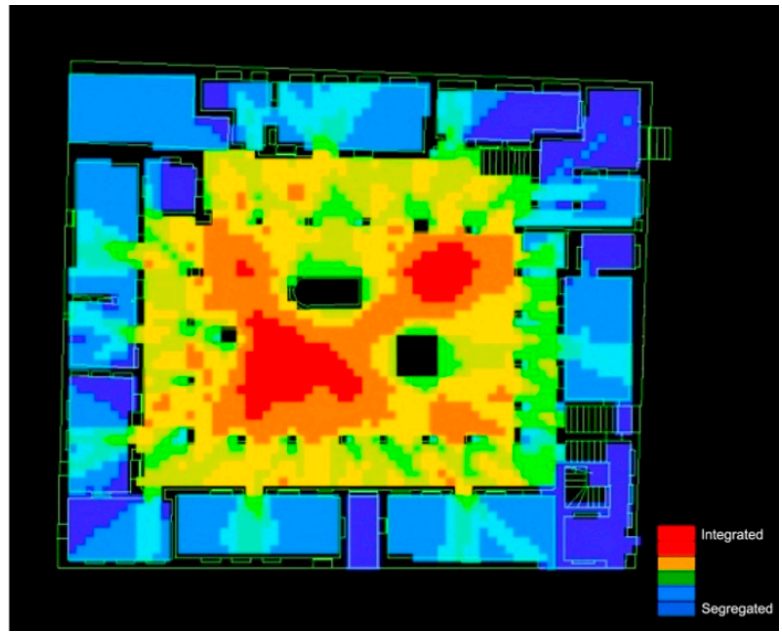

(b)

Figure 10. (a) Layout with courtyard indicated in light gray and rooms in dark gray and (b) visibility graph analysis (VGA) of Vernacular House, Case Study 2 showing integration in a range from red (integrated) through orange, yellow, green, light blue to blue (segregated) (Source: Authors).

Socio-cultural Factors: (a) Privacy: In the VGA analysis graph, connectivity gradually increases from the private rooms on the edges toward the core of the house, where the porch presents an intermediate connection to the highly connected central courtyard. Entry points gradually open into the porch, which entirely opens into the main courtyard of the house. This sequence of spatial arrangement reflects the color-coded layout of connectivity. Within the courtyard itself, some areas are less connected than others, due to visual barriers and physical blocks such as the small landscape features and palm trees. (b) Gender Spatial Segregation: The entry points on the east and south demonstrate low connectivity, responding to the socio-cultural pattern of gender segregation to avoid direct exposure of the household to the public street. Dedicating a separate staircase entry might also refer to a gender spatial segregation pattern related to extended family, as mentioned previously. (c) Hospitality: Due to the unclarity of the Majlis section or spaces in the collected references, the authors expect that one of the rooms in the upper northern section might be a Majlis room. These rooms are near to the main entrance and spatially arranged with doors and partitioned walls inside.

System of Activities: (a) Public Use Spaces: The intermediate space surrounding the courtyard is the center of activities. Such spaces include covered porches and arcades decorated with simple ornaments and modest architectural features. The most intermediate circulation spaces comprise no less than a third of the total house area. In the VGA analysis graph, connectivity is the highest in clear areas of the open-air courtyard. Yet, most of the yellow to light green shaded areas are intermediate 
connectors. The nature of activities in such spaces involves shaded circulation, on-ground seating areas, gatherings, and leisure spots for the family members. This pattern of courtyard style and ratio supports family activities and the full spatial utilization of the house during different climatic conditions. In the central courtyard, there are planters of shading trees that provide a pleasant view and an enhanced microclimate. (b) Private Use Spaces: The private rooms are spacious and accessible mainly through single doors. In the VGA analysis graph, the range of blue that radiates from the door indicates that the room is slightly exposed when the door is open, yet the corners of the rooms are always private. These patterns support storage activities in such private rooms, or the allocation of the bed within the bedroom to avoid visual disturbance. Thus, the meaning of intermediate spaces is not limited to architectural connectors, but rather gradual elements of the housing spatial form that secure other private areas and allow inhabitants a flexible utilization of each space, within the accepted limits of privacy.

\subsection{Vernacular House-Case Study 3: Al Jaber House|Al Asmakh, Doha|Built 1935}

Spatial Form: (a) Public Use Spaces: The house is in one of the most valuable residential districts in old Doha, namely the Al Asmakh neighborhood. The significance of the area lies in its proximity to Doha's old port and the active commercial centers so that access to the market and other public spaces was historically assured. The house has a typical architectural configuration with its walled courtyard and L-shaped room arrangement (Figure 11). The house entrance represents its only decorative architectural feature in addition to the high-walled fence surrounding the courtyard. (b) Private Use Spaces: The house consists of eight rooms with a simple architectural style. Bathrooms locate in the corner where the north-east bathroom was originally built over a well. A raised porch leads to the private rooms in addition to shaded iwan. The rooms have typical traditional roofs of organic beams.

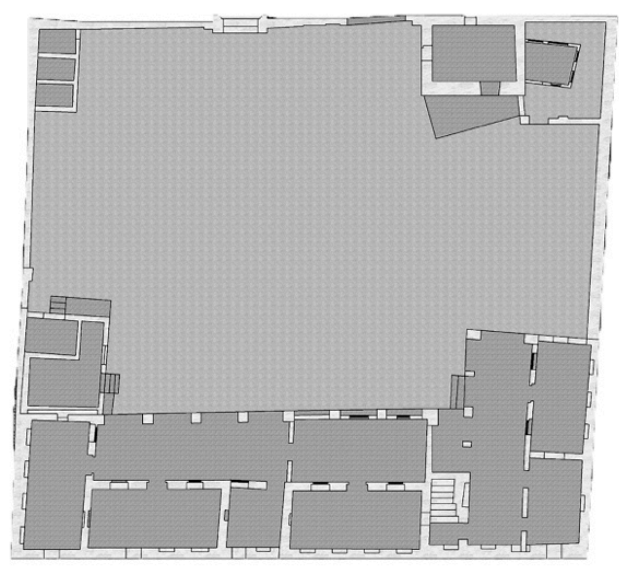

(a)

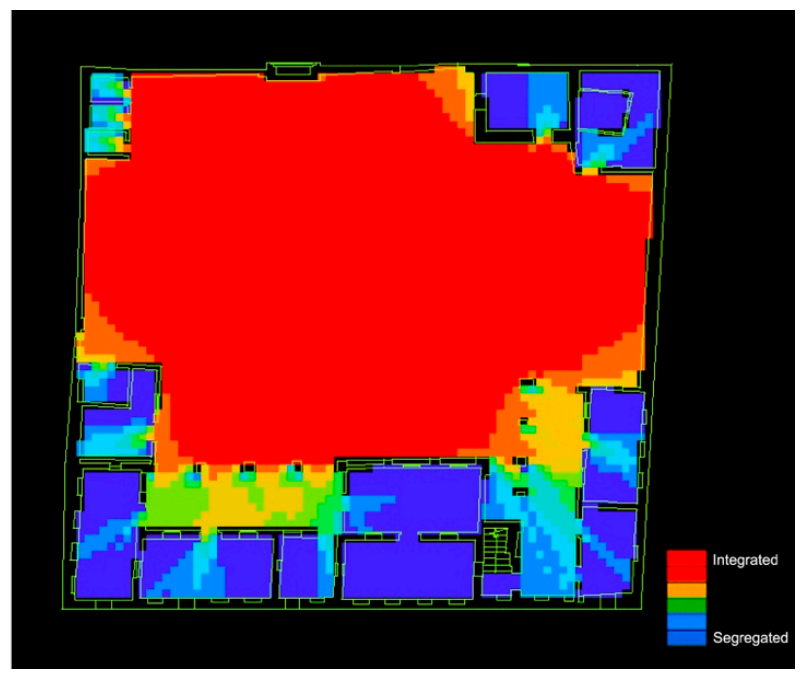

(b)

Figure 11. (a) Layout with courtyard indicated in light gray and rooms in dark gray and (b) visibility graph analysis (VGA) of Vernacular House, Case Study 3 showing integration in a range from red (integrated) through orange, yellow, green, light blue to blue (segregated) (Source: Authors).

Socio-cultural Factors: (a) Privacy: This house presents extreme connectivity, where intermediate spaces are only indicative of the porches and iwans. It is related to the spacious area covered by the open-air courtyard and the minimal space occupied by rooms and other functional areas, resulting in less privacy in the courtyard. Surrounding the household with a high fence wall might raise the need for extreme visual privacy to cover the wide-open space. (b) Gender Spatial Segregation: The existence of a separated room and a bathroom near the entrance might signify a pattern that relates to gender spatial 
segregation. The separated room might belong to domestic workers in the house, who could be male. It also could be a small Majlis space dedicated to male visitors. (c) Hospitality: The main entrance to the south reveals high connectivity to the rest of the household. Meanwhile, the khokha design of the door prevents a direct exposure to the household and allows visitors to access in a respectful manner. The design of the khokha door regulates access to the household in a flexible way; family members and guests use the small door individually, while the large door is used for services, piles, and other larger packs. In addition, rooms are located relatively far from the main entry point, reducing exposure and maintaining the family's privacy.

System of Activities: (a) Public Use Spaces: The courtyard is clearly the setting for public activities. It has a large outdoor seating area and a shading tree in addition to the wells. Such elements add further value to the courtyard while supporting its use for gatherings, leisure, and plantation. (b) Private Use Spaces: Porches and circulation spaces regulate the use of private rooms on the rear end of the courtyard. The private rooms have minimal exposure due to spatial location and architectural elements. Even for rooms that face the main entrance, their side entrances prevent them from direct visual exposure and maintain their privacy. The room located on the west that opens immediately to the courtyard is kitchen space. Part of the kitchen is un-roofed, where the activity of cooking and grilling takes place, allowing smoke and smells to escape and maintain the olfactory privacy of the private rooms.

\subsection{Vernacular House-Case Study 4: Ismail Mandani House|Al Asmakh, Doha|Built around 1940}

Spatial Form: (a) Public Use Spaces: This two-story house has an entrance gate at the south-western corner (Figure 12). The courtyard is a trapezoid surrounded by fifteen rooms on the ground floor, while only four rooms occupy the first floor. As a socio-economic trend, wealthy families in the old Qatari society usually construct their houses in two levels due to financial affordability. The main access to the house is through its south-western entrance beside a Majlis room. The house plot mostly allocates to family uses occupying the northern, eastern, and southern walls. (b) Private Use Spaces: The courtyard has two iwans, which are vaulted rectangular spaces walled on three sides and open on one side. The first floor is accessible through a concrete staircase leading to four rooms. An arcaded porch surrounds some of the upper floor rooms.

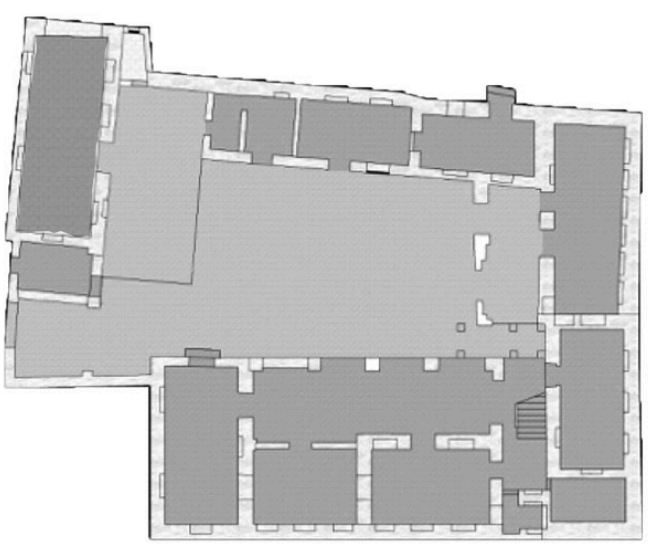

(a)

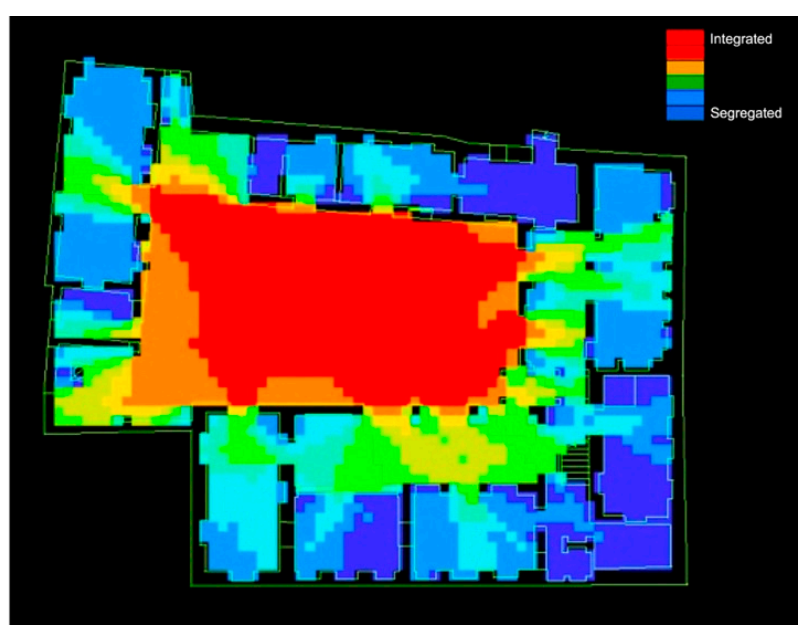

(b)

Figure 12. (a) Layout with courtyard indicated in light gray and rooms in dark gray and (b) visibility graph analysis (VGA) of Vernacular House, Case Study 4 showing integration in a range from red (integrated) through orange, yellow, green, light blue to blue (segregated) (Source: Authors).

Socio-cultural Factors: (a) Privacy: The courtyard exhibits a high connectivity pattern to the surrounding spaces. The rest of the spaces, including the entrance to the southwest, have low 
connectivity, which might contradict the purpose of entry at this location. Considering the socio-cultural pattern of privacy in the spatial form of Muslim homes, "entrance doors in traditional Muslim homes are placed away from the main street and not directly facing the opposite neighbors" [35] (p. 15). The intermediate spaces of the iwans present a medium-connectivity pattern, which proves their functionality as mediating spaces that utilize the internal configuration of the house to support privacy, rather than imposing temporary solutions such as furniture or screens. (b) Gender Spatial Segregation: The allocation of the Majlis section adjacent to the main entrance is a spatial solution to allow male visitors immediate access into the space, securing the house sanctity. In addition, first floor rooms were likely used by women and children due to the existence of seating areas with parapets and blinds to avoid exposure. (c) Hospitality: The house has two Majlis spaces; one is the main guest room next to the entrance. The other Majlis room on the first floor in a well-ventilated and climatically pleasant area, supporting its sure as an occasional guest reception space.

System of Activities: (a) Public Use Spaces: The ground floor level is the setting for public use spaces. The courtyard represents an open space unifying the plot. The main entrance opens into an iwan, which might be the setting for public gatherings and family gatherings. Behind the iwans of the ground floor are private rooms that maintain their visual and functional privacy. Shared public services also occupy the ground floor level, such as bathrooms, lobbies, and kitchen. (b) Private Use Spaces: The first-floor rooms are the settings for private use spaces. The courtyard house has four upper floor rooms and a spacious roof covered with a high parapet. Roofs were part of the social life of the old Qatari family; they were mostly used as recreational spaces and sleeping spaces during the summertime since the night breeze is cooler at elevated levels. Thus, the meaning of the roof could be an alternative living area that supports family leisure and creates the anticipated linkage between residential architecture and climatology.

\subsection{Comparative Analysis Based on Relational (Unjustified) Graphs}

We present here a brief analysis of the similarities and differences between the four houses. A possible comparative aspect is the relational graphs in (Figure 13), based on convex spaces for the ground floor plans (see Appendix A for more information on convex spaces).

As a general pattern, all four courtyard houses have a central, integrated space that represents the courtyard where visibility is a maximum. Thus, the pattern proves to support the argument of this paper that courtyards are central in the social and spatial arrangement of traditional Qatari domestic functions. Another common noticeable pattern is the intermediation of iwans and porches that create a gradual level of visibility, refining the high connectivity of the courtyard as we approach to the surrounding private rooms and bedrooms. Most of the private rooms in the four houses connect indirectly to the courtyard through such iwans and porches, adding further emphasis about the value of the socio-cultural factor of privacy and its excessive influence on the spatial form of the courtyard house.

In terms of other spaces, we treated the thresholds between several rooms as separate small spaces due to the thickness of walls in traditional Qatari construction as in the cases of Saif, Al Jaber and Mandani houses. This fact leads to the possibility of creating further central nodes branching from the main courtyard, which supports the need for growth and family expansion as a socio-cultural practice. To summarize the comparative analysis based on relational graphs, the main point is even though the courtyard house model seems relatively simple, the spatial layout in such houses are capable of extreme sophistication and differentiation of room types for privacy, gender, and function based on design. 


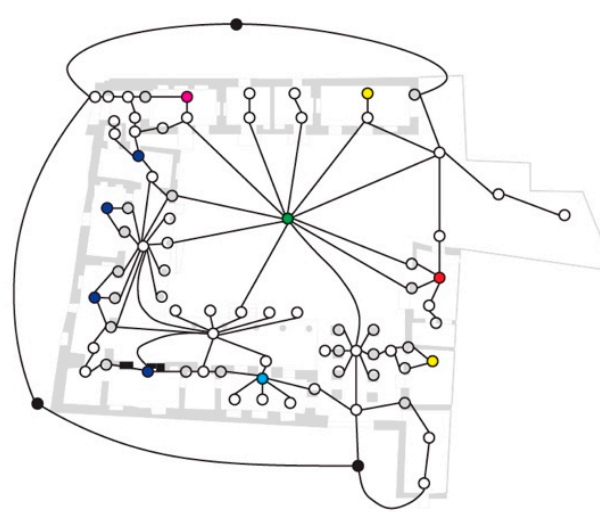

a. Noura Bint Saif House

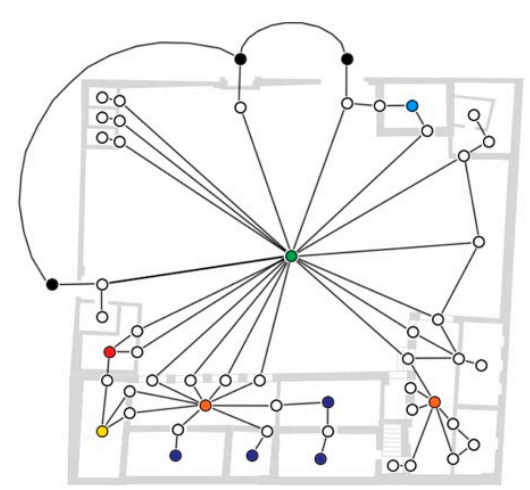

c. Al Jaber House

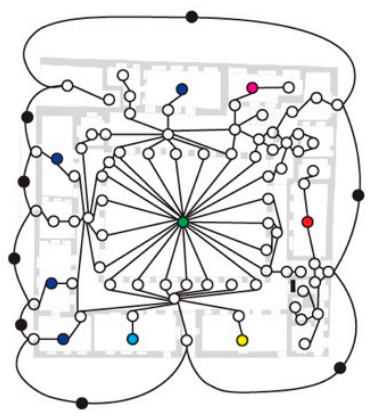

b. Faraj Al Ansari House

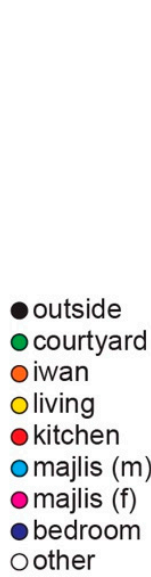

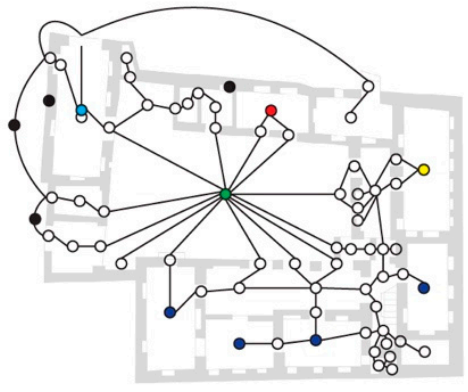

d. Ismail Mandani House

Figure 13. Relational graphs based on convex spaces for the ground floor plan of four traditional Qatari courtyard houses with color-coding of the functional spaces. (a) Noura Bint Saif House (b) Faraj Al Ansari House, (c) Al Jaber House, (d) Ismail Mandani House

\section{Discussion and Conclusions}

The study investigated the extent to which the spatial form and distribution of old Qatari vernacular houses of courtyard typology embedded societal patterns and values of the society. The paper offers a cultural-heritage framework to preserve the distinguished vernacular residential architecture in Qatar. The investigation includes the analysis of human behavior and activities within selected courtyard houses to prove the embedment of socio-cultural factors in the spatial form of the houses. The paper presents four courtyard houses and analyses them based on clearly-defined criteria of analysis, including the (i) spatial form, (ii) socio-cultural factors of privacy, gender spatial segregation and hospitality, and (iii) system of activities. Thus, the outcome of the analysis indicates a strong interconnection between the three criteria, which are common in the presented cases yet take altered approaches based on each houses' architectural and spatial dynamics. The outcomes of the research paper validate the hypothesis that the spatial form of these vernacular houses does express culture as a way of life where human activities are necessary as a source of cultural understanding. Thus, the cultural heritage framework for the preservation of vernacular architecture in Qatar is not limited to the built form but also involves intangible, socio-cultural, and behavioral aspects.

The findings help to support the social sustainability of architecture in Qatar, marking the progress of housing as a phenomenon contributing to the country's sustainable urban development. Through a multi-layered methodology that includes the utilization of space syntax and theory and tool, the research study presents an assessment of vernacular houses in Qatar about spatial form, socio-cultural patterns, and human activities. The findings shed light on the influence of privacy, gender segregation, and hospitality on the overall built form of the vernacular Qatari housing unit, which in turn has 
an impact on the nature of activities carried out by household inhabitants. Also, vernacular houses are highly governed by Islamic and cultural norms, which represent typical architectural trends in the region.

The cases from the past indicate that the relationship between local inhabitants and the courtyard space within the house is strong since a significant part of the daily domestic as well recreational activities occurred in the areas adjacent to the main courtyard in addition to the central courtyard itself. Besides socio-cultural factors, we may attribute other reasons for the existence of climatic moderation techniques bordering the courtyard, such as vaults and porches, and native vegetation, which offers opportunities for the gradual patterning of visual connectivity in the household. Thus, the spatial formation of the courtyard house establishes a core for outdoor high connectivity activities, while creating intermediate spaces to filter the visual connectivity and allocate privatized areas in the secured, less-connected parameter of the house plot.

The architectural sociology of housing in Qatar requires further attention due to the challenges of contemporary architecture. It also requires establishing references to historical built structures and analytical studies of vernacular architectural trends and forms as a source of cultural heritage knowledge. Until recently, problems of residential architecture have emerged as the disturbance of the built form, unresponsive foreign plans of residential architecture as well as local dissatisfaction with the poorly integrated modern villas continuously readapted to meet the socio-cultural needs of their inhabitants. Socio-spatial relationships in the housing unit profoundly influence the development of Qatari residential architecture. It is especially true in the contemporary era, where locally intensive practices are crucial to reviving the urban identity of cities and settlements. To maintain civic identity in social and architectural terms, the following aspects of socio-spatial design should assume a higher priority in new housing:

1. Maintaining the privacy of the housing unit through architectural interventions that are designed based on careful data collection about human behavior and anticipated user activities, along with proper precedent analysis. The design must avoid reactive solutions that result in formative difficulties and inharmonious built form in addition to avoiding loss of architectural solidity and simplicity established by the vernacular models of housing in Qatar.

2. Gender segregation is a cultural norm of Qatari society, despite recent global debates advocating for gender equality and rights in other social and urban contexts [70]. It is a social norm long practiced in Qatar in a peaceful, thoughtful manner, leading to clear behavioral and socio-cultural activities that influenced the spatial form of the vernacular architecture in a constructive approach.

3. Importing/copying forms from vernacular architecture has to be rethought in the contemporary context. Recently, many contemporary houses have copied certain architectural elements as decorative touches on the housing facade. Yet, there is a lack of design schemes that integrate the courtyard typology into contemporary layouts or allow owners and dwellers to establish coherent utilization of all spaces and spatial areas in an adaptive manner. For instance, the spacious areas assigned for Majlis units are mostly idle and underutilized due to occasional social events. Such spaces could become more adaptive through innovative architectural and interior design solutions.

\section{Contribution to Knowledge}

The research study contributes to our knowledge about the socio-spatial study of housing environments in Qatar and the MENA/Arab Gulf region, which faces a rarity of research interest and publications. It also defines a cultural heritage framework to preserve the distinctive Qatari vernacular residential architecture, based on a clear set of analytical criteria. Thus, this research study merges the gap between residential architecture and sociology by providing the missing linkage in the context of Qatar. In terms of the study's originality and applicability in other contexts outside the MENA region, the authors believe globalization causes similar trends and challenges across the world, especially those concerning vernacular architecture and cultural heritage preservation. Thus, we assume the 
methodology to be applicable in the international level, serving as an assessment method and a tool to shed light on the marginalized local practices and to support socio-cultural sustainability.

\section{Limitations and Implications for Practice and Advancement of Research}

The study has limitations in terms of the representativeness of the selected units of analysis. The number of housing units selected for review, limited to four vernacular examples, might affect the reliability of the findings in this paper. However, there is a scarcity of archived material and architectural references documenting vernacular houses in Qatar since the field of historical building preservation and conservation is relatively new to the country. Another reason for this relates to the unclarity of the courtyard style and ratio in some vernacular houses that the authors collected and reviewed, which would limit the analysis in terms of connectivity and spatiality urging the authors to select the most obvious cases with a clear courtyard-to-room or solid-to-void ratio.

In the results section, the authors present the visibility graph analysis (VGA) of the ground floor levels only, which might present a possible limitation. Most of the courtyard houses in old Doha had no more than a ground level due to the constrains of construction and affordability. Meanwhile, it was common that some wealthy families would add first-floor levels to their houses as we confirmed in the second case of Faraj Al-Ansari house and the fourth case of Ismael Mandani house. Thus, the authors limit the VGA of these houses to the ground floor level only while they consider the cumulative analysis of the rooftop and the first-floor levels when applicable.

To strengthen the outcomes of the research study, we recommend further study based on more case study samples, which would enrich the discussion and improve the outcomes of the space syntax analysis, thus enhancing the reliability of the findings in this paper. The list below (Figure 14) illustrates other vernacular Qatari houses as a recommendation for further investigation. It would provide a future opportunity for researchers and architects to examine the houses in terms of the socio-cultural imperatives and to test the replicability of the methodology.

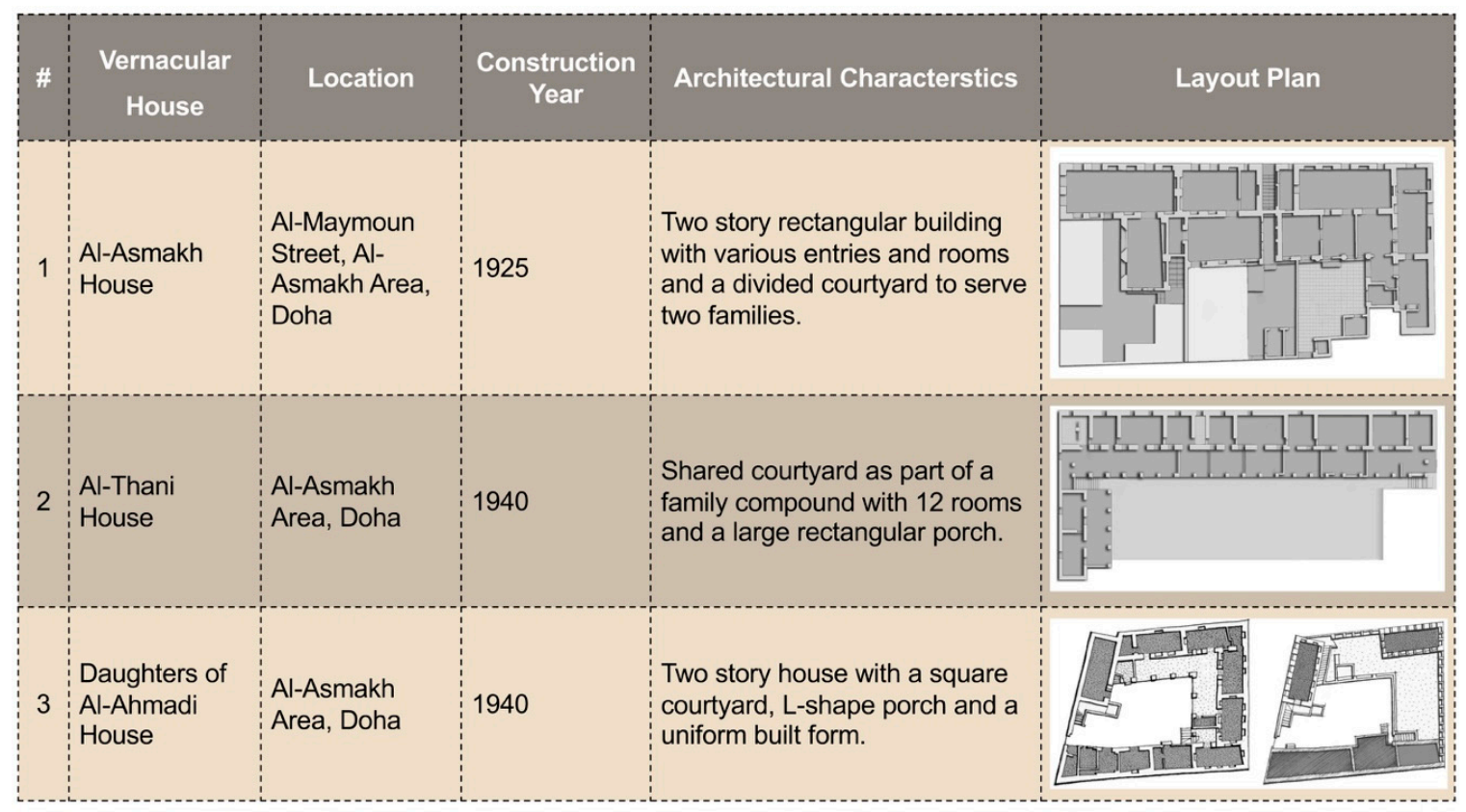

Figure 14. List of other Qatari vernacular courtyard houses the authors suggest for the advancement of the research.

Finally, instead of selecting individual housing units, it is recommended to perform the analysis on a neighborhood scale where aspects of the urban fabric become part of the study. Such elements 
could involve the street level, solids and voids, public spaces, and other important components of the urban morphology and the contextual socio-cultural interconnections.

Author Contributions: The authors contributed to this research study as follows: Conceptualization, A.A.-M., R.F., M.D.M.; methodology, A.A.-M., R.F., M.D.M.; software, A.A.-M., M.D.M.; validation, A.A.-M.; formal analysis, A.A.-M.; investigation, A.A.-M.; resources, A.A.-M., R.F., M.D.M.; data curation, A.A.-M.; writing-original draft preparation; A.A.-M.; writing-review and editing, A.A.-M., R.F., M.D.M.; visualization, A.A.-M., R.F., M.D.M.; supervision, R.F., M.D.M.; project administration, A.A.-M., R.F.; funding acquisition, R.F. All authors have read and agreed to the published version of the manuscript.

Funding: Open access publication of this paper was supported by Qatar University (Grant ID: QUCG-CENG-20/21-1).

Acknowledgments: The authors would like to acknowledge the support of Qatar University for creating an environment that encourages academic research and unlocks the creative potential of budding researchers. Also, the authors would like to acknowledge the support of Andra-Theodora Radu, University of Architecture and Urbanism Ion Mincu in Bucharest, Romania, for assisting Mark David Major, who prepared the relational graphs for the Saif, Al Ansari, and Mandani houses in the sample of this paper. This paper was subject to a Double-Blind Peer Review process. Once accepted for publication, the journal 'Sustainability' offered the authors the choice to publish this article on open access (OA). Finally, the authors thank the anonymous reviewers for their comments, which contributed to an improvement of this paper.

Conflicts of Interest: The authors declare no conflict of interest.

\section{Appendix A About Space Syntax}

Our built environment is both a product of society and an influence on society. Space syntax is an international research program of academics and practitioners scientifically investigating spatial networks from the single building to entire metropolitan regions to better understand the role of built space in society $[64,68,71,72]$. Founded in the late 1970 s and early 1980 s by Bill Hillier, Julienne Hanson, John Peponis, Alan Penn, and many others in The Bartlett at University College London, space syntax has developed a set of techniques for the simple representation and mathematical measurement of architectural and urban space over the last 40 years [11,68,73-77]. Today, the international space syntax community composes hundreds of researchers and practitioners in more than forty countries around the world.

Representations in space syntax are usually plan-based using objective, easily understood constraints of the built environment for the most generic of human uses such as movement, occupation, and visibility because we are forward-facing, bipedal creatures normally bound by gravity $[71,72]$ (Figure A1). A point in space is the simplest notion on which to build a geometry with no size, only position. The number of points in any space will be infinite without a resolution-defining the bounds of a space and 'size' for the points—such as the average standing area of a normal human being $\left(0.28 \mathrm{~m}^{2}\right)$ [77]. Movement tends to be linear because we are bipedal, forward-facing creatures bound by gravity. The axis or line of sight and movement (e.g., axial line) represents an idealization because a line is a set of points having a length but no width or depth. The matrix of longest and fewest (i.e., most strategic) lines of sight and access completely covering all spaces of a built environment as defined by its built surfaces (walls or facades) is the axial map [68]. The axial map is the most common reference to a 'space syntax model' for forecasting (60-80\% accuracy) of pedestrian and vehicular movement in the urban environment $[75,76]$. The occupation of space tends to be convex where everyone can see and be seen by everyone else such as a group of people gathered in a circle or a room. All points are visible to all other points in a convex space. The collection of all convex spaces composing a built environment is the convex map, which tend to be more useful for the analysis of buildings [64,71,74]. The potential for seeing and moving is a visual field, which is visible and accessible space from which we might see or move as defined from a point or set of points such as a line of sight and movement or convex space [73]. The matrix of all visual fields from a gridded set of points to all others in a built environment is a visibility map [77]. Space syntax uses combinations of these simple descriptions-point, line, space, field-to create layered representations of the built environment. We can measure the matrices of these representations using topological graph theory to mathematically quantify the configurational relationship of all spaces—point, line, space, visual field — to all others or 
within a set range. Configuration is a relational system where any local change in a system can have global effects across that system to varying degrees dependent on the size of the system relative to the significance of the change itself within that system [71] (Figure A2).
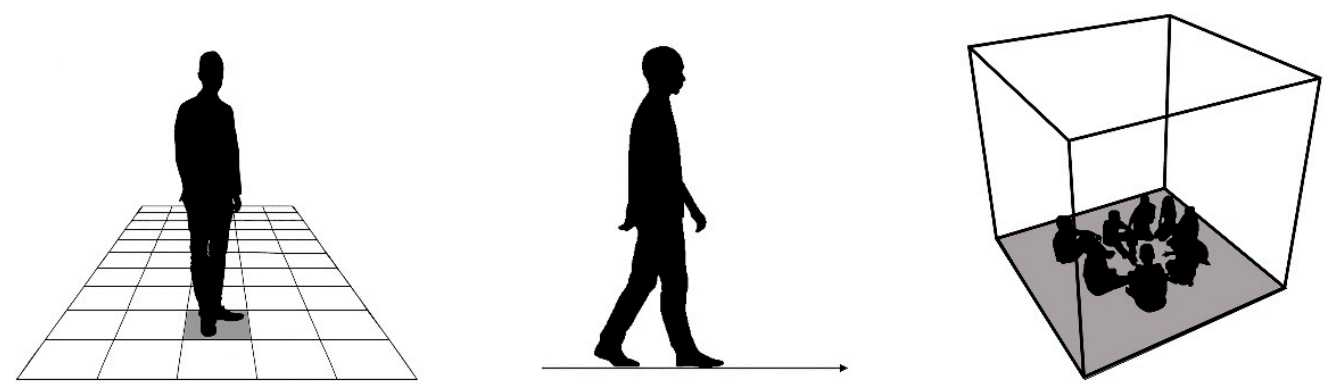

Figure A1. Representing (top, left to right) a point, line, and convexity ('the quality or state of being convex') in space syntax and (below, left to right) a visual field (in dark gray) from a point, line, and convex space (in light gray) in the floor plan of Radwani House in Doha, State of Qatar. (Source: Mark David Major).
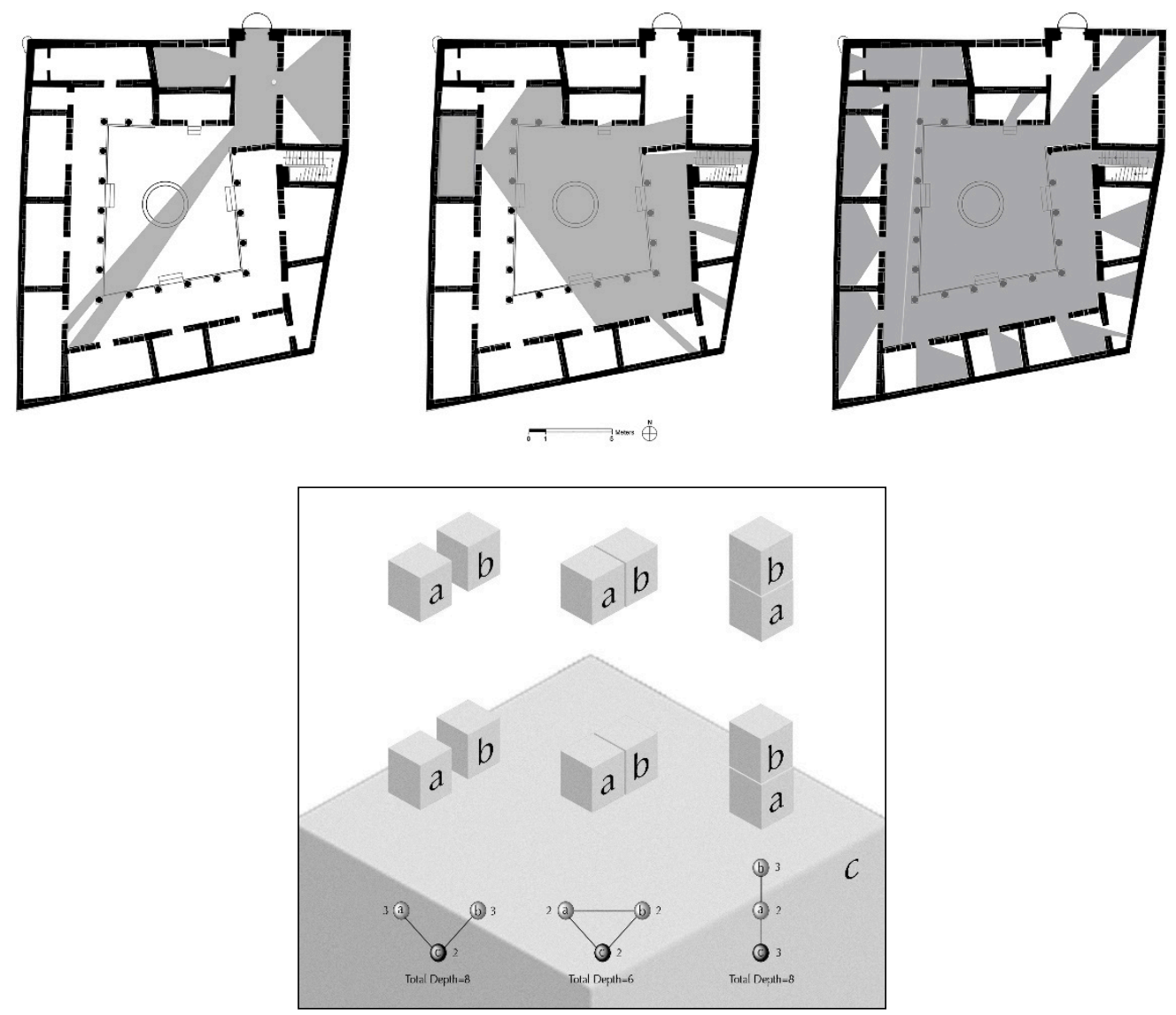

Figure A2. The basics of configurational measurements using topological graph theory where (top row) two objects labelled A and B are similarly-related until (middle row) the introduction of a third object labelled C (such as the surface of the Earth). All three objects now have different configurational relationships based on connection or permeability, as represented (bottom row) in the justified graphs where the object is represented as a node and their relation as a line (Source: Major, 2018 after Hillier, 1996) [71,72].

Configurational measures offer a scientific basis to implicate or dismiss the designed spatial network as a factor in social, functional, and/or cultural outputs. Space syntax software also incorporates metric parameters such as the length of streets/street segments and the plan area/perimeter surface area 
of visual fields. Over four decades, researchers have developed a diverse number of configurational and metric measures using space syntax. Some are more useful than others, and sometimes it can take years of testing to confirm or refute their usefulness. It can be overwhelming for those unfamiliar with space syntax. Generally, the most useful are:

Connectivity is a simple measure of how many other spaces does a single space immediately connect to within the network.

Integration is the relativized mean depth of a space in relation to all other spaces in a network based on changes of direction using connectivity (see above). It represents how integrated/shallow or segregated/deep is a space within a spatial network. It demonstrates the pattern of 'to-movement' for those spaces most likely used for journeys from anywhere to everywhere else in the spatial network. Researchers can set the radii of integration measures based on specified parameters such as global integration (radius $=\mathrm{n}$ ) and local integration (radius $=3$ ).

\section{Modeling for Visibility Graph Analysis (VGA)}

Space syntax software can conduct Visibility Graph Analysis (VGA) based on the matrices of all visual fields as defined by points in space of a plan, be it at the building or urban level. VGA can calculate both metric and configuration parameters of the visual fields. This type of analysis requires a closed system. This means defining a reasonable boundary for an urban area or building. In the case of buildings, this is usually a simple decision based on drawing a boundary around the plan without any access of the outside world, as if locking all the doors providing access the exterior. In the case of urban areas, the drawing of the boundary tends to follow the same rules of thumb for defining boundaries in the axial mapping of urban case studies, i.e., topographical barriers such as coastlines or mountains, major transportation corridors such as highways and major roads, railroad lines, and other urban elements such as large parks and green belts. The larger the metric area of the model, then longer the processing takes for the computer software, so careful selection of a bound for the plan is an important consideration. The spatial network requires realistic constraints. The computer establishes a grid over a plan where each grid element represents a 'point' in space. It is possible to define the metric area of this grid element representing a point in space. The smaller the metric area of a grid element, the longer the processing time for the various metric and configurational measurements using visibility graph analysis.

For example, the grid element representing a point in space for visibility graph analysis of Radwani House in Doha, State of Qatar is $0.5 \mathrm{~m} \times 0.5 \mathrm{~m}$ or $0.25 \mathrm{~m}^{2}$. This is about the same as the standing area occupied by an average human being $\left(0.28 \mathrm{~m}^{2}\right)$ (Figure A3). This model of Radwani House eliminates the central well and marginal elevation changes from the plan for a representation of pure visibility, i.e., everything you can see but not necessarily everything you might have to navigate in movement through the house such as walking around the well or stepping up (two steps or $\sim 40 \mathrm{~cm}$ ) to the veranda. The computer then virtually draws the $360^{\circ}$ visual field from each grid element in space and calculates metric and spatial characteristics using topological graph methods. The computer colors the measurements in a range from red to orange, yellow, green, light blue to dark blue where red represents high/near and dark blue represents low/far, depending on the specific measurement [77]. 


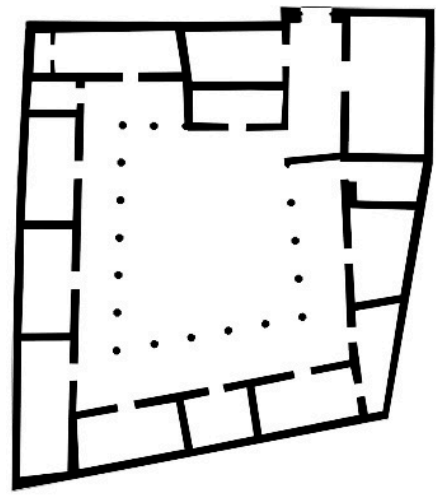

(a)

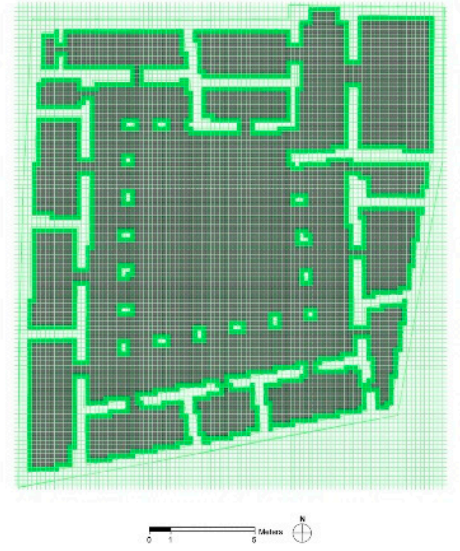

(b)

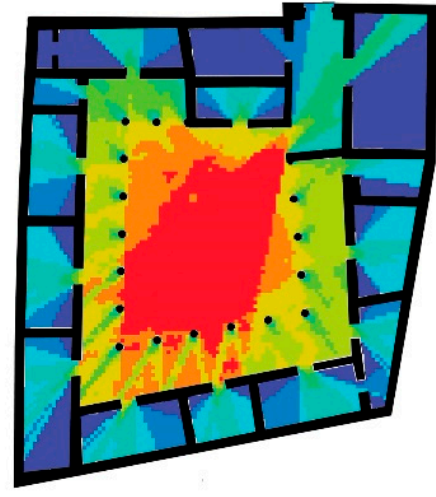

(c)

Figure A3. The procedure for modeling for visibility graph analysis (VGA) based on the (a) Floor Plan, (b) Filling the Overlay Grid, and (c) Processing for Visual Integration in Radwani House in Doha, Qatar (Source: Mark David Major).

\section{References}

1. Elsheshtawy, Y. The Evolving Arab City: Tradition, Modernity and Urban Development; Routledge: Oxfordshire, UK, 2011.

2. Nooraddin, H. Architectural Identity in an Era of Change. Dev. Ctry. Stud. 2012, 2, 81-96.

3. Salama, A. Architectural Identity in the Middle East: Hidden Assumptions and Philosophical Perspectives. In Shores of the Mediterranean: Architecture as a Language of Peace; Mazzoleni, D., Ed.; Intra Moenia: Napoli, Italy, 2005; pp. 77-85.

4. Petruccioli, A. House and Fabric in the Islamic Mediterranean City. In The City in the Islamic World; Jayyusi, S.K., Ed.; Brill, Hotei Publishing: Boston, MA, USA, 2008; Volume 2, pp. 851-875.

5. Ragette, F. Traditional Domestic Architecture of the Arab Region; Edition Axel Menges: Stuttgart, Germany, 2006.

6. Salama, A. A Typological Perspective: The Impact of Cultural Paradigmatic Shifts on the Evolution of Courtyard Houses in Cairo. METU JFA 2006, 23, 41-58.

7. Zhang, D. Courtyard Housing and Cultural Sustainability: Theory, Practice, and Product; Routledge: New York, NY, USA, 2016.

8. AL-Mohannadi, A.; Furlan, R.; Major, M. Socio-Cultural Factors Shaping the Spatial Form of Traditional and Contemporary Housing in Qatar: A Comparative Analysis Based on Space Syntax. In Proceedings of the 12th International Space Syntax Symposium Proceedings, Beijing, China, 8-13 July 2019; pp. 1-19.

9. Rapoport, A. House Form and Culture; Prentice-Hall, Inc.: Upper Saddle River, NJ, USA, 1969.

10. Glassie, H. Folk Housing in Middle Virginia: A Structural Analysis of Historic Artifacts; University of Tennessee Press: Knoxville, TN, USA, 1976.

11. Hillier, B. The Architecture of the Urban Object. Ekistics 1989, 334, 5-20.

12. Groizard, J.L.; Santana-Gallego, M. The destruction of cultural heritage and international tourism: The case of the Arab countries. J. Cult. Herit. 2018, 33, 285-292. [CrossRef]

13. Vecco, M.F. Imperiale Cultural heritage in times of armed conflicts in the Middle East: Much more than material damage? Introduction. J. Cult. Herit. 2018, 33, 262-263. [CrossRef]

14. Khalaf, S. The evolution of the Gulf city type, oil, and globalization. In Globalization and the Gulf; Fox, J., Sabbah, N., Mutawa, M.A., Eds.; Routledge: London, UK, 2006; pp. 244-265.

15. Law, R.; Underwood, K. Msheireb Heart of Doha: An Alternative Approach to Urbanism in the Gulf Region. Int. J. Islam. Arch. 2012, 1, 131-157. [CrossRef]

16. Petruccioli, A. After Amnesia: Learning from the Islamic Mediterranean Urban Fabric; ICAR: Bari, Italy, 2007; ISBN 88-95006-03-8.

17. Adham, K. Rediscovering the Island: Doha's Urbanity from Pearls to Spectacle. In The Evolving Arab City: Tradition, Moderniy and Urban Development; Elsheshtawy, Y., Ed.; Routledge: London, UK, 2008. 
18. Furlan, R.; Faggion, L. The Souq Waqif Heritage Site in Doha: Spatial Form and Livability. Am. J. Environ. Eng. 2015, 5, 146-160.

19. Nagy, S. Keeping Families Together: Housing policy, social strategies and family in Qatar. MIT Electron. J. Middle East Stud. 2004, 4, 42-58.

20. ICOMOS. Principles and Guidelines for Managing Tourism at Places of Cultural and Heritage Significance; International Council on Monuments and Sites: Gland, Switzerland, 2002.

21. Ferretti, V.; Bottero, M. Giulio Mondini Decision making and cultural heritage: An application of the Multi-Attribute Value Theory for the reuse of historical buildings. J. Cult. Herit. 2014, 15, 644-655. [CrossRef]

22. UNESCO. Culture: Urban Future. Global Report on Culture for Sustainable Urban Development; United Nations Educational, Scientific and Cultural Organization: Paris, France, 2016.

23. Vaz, E.; Kourtit, K.; Nijkamp, P.; Painho, M. Spatial analysis of sustainability of urban habitats, introduction. Habitat Int. 2015, 45, 71-79. [CrossRef]

24. Hassan, F.; Trafford, A.; de Youssef, M. Cultural Heritage and Development in the Arab World; Bibliotheca Alexandrina: Alexandria, Egypt, 2008; ISBN 978-977-452-133-1.

25. QNDF. Qatar National Development Framework 2032; Ministry of Municiplity and Environment: Doha, Qatar, 2016.

26. Setyowati, D.L.; Hairumini, S.; Budi, T.; Rais, M. Perception and Local Initiation of Communities in Maintaining the Traditional Acehnese Houses. In Proceedings of the UNNES International Conference on Research Innovation and Commercialization, Ungaran, Indonesia, 10 November 2018.

27. Almahmoud, S. The Majlis Metamorphosis: Virtues of Local Traditional Environmental Design in a Contemporary Context; Virginia Commonwealth University: Richmond, VA, USA, 2015; Volume MFA.

28. Dunham, D. The Courtyard House as a Temperature Regulator. Athens Cent. Ekistics 1961, 11, 181-186.

29. Edwards, B.; Sibly, M.; Land, P. Courtyard Housing: Past, Present and Future; Taylor \& Francis: Abingdon, UK, 2006.

30. Khalili, S. The Courtyard House: Using Cultural References of the Past as an Alternative to Ottawa's Current Housing Typologies; Carleton University: Ottawa, ON, Canada, 2012.

31. Alkhalidi, A. Sustainable Application of Interior Spaces in Traditional Houses of the United Arab Emirates. Procedia Soc. Behav. Sci. 2013, 102, 288-299. [CrossRef]

32. AL-Mohannadi, A.; Furlan, R. Socio-cultural patterns embedded into the built form of Qatari houses: Regenerating architectural identity in Qatar. J. Urban Regen. Renew. 2019, 12, 336-358.

33. AL-Mohannadi, A. The Spatial Culture of Traditional and Contemporary Housing in Qatar. A Comparative Analysis based on Space Syntax. Master's Thesis, Qatar University, Doha, Qatar, 2019.

34. Sobh, R.; Belk, R.W. Privacy and Gendered Spaces in Arab Gulf Homes. Home Cult. 2011, 8, 317-340. [CrossRef]

35. Othman, Z.; Aird, R.; Buys, L. Privacy, modesty, hospitality, and the design of Muslim homes: A literature review. Front. Archit. Res. 2015, 4, 12-23. [CrossRef]

36. Bahammam, A.S. Architectural Patterns of Privacy in Saudi Arabian Housing. Master's Thesis, McGill University, Montreal, QC, Canada, 1987.

37. Farah, E.A.; Klarqvist, B. Gender Zones in the Arab Muslim House. In Proceedings of the 3rd International Space Syntax Symposium; Georgia Institute of Technology, Atlanta, GA, USA, 7-11 May 2001.

38. Campo, J.E. The Other Sides of Paradise: Explorations into the Religious Meanings of Domestic Space in Islam; University of South Carolina Press: Columbia, SC, USA, 1991.

39. Cooper, B.M. Gender, Movement, and History: Social and Spatial Transformations in 20th Century Maradi, Niger. Environ. Plan. D Soc. Space 1995, 15, 195-221. [CrossRef]

40. Nageeb, S.A. New Spaces and Old Frontiers: Women, Social Space, and Islamization in Sudan; Lexington Books: Lanham, MD, USA, 2004.

41. Rababah, H.M. Rules and Ethics of Hospitality in Islam. J. Cult. Soc. Dev. 2016, 20, 44-56.

42. Nagy, S. Making room for migrants, making sense of difference: Spatial and ideological expressions of social diversity in urban Qatar. Urban Stud. 2006, 43, 119-137. [CrossRef]

43. Salama, A.M. Lecture 6: Incorporating Lifestyle Theories: An Inquiry Process for Affordable Housing in the Gulf; Qatar University: Doha, Qatar, 2013.

44. Bekleyen, A.; Dalkil, N. The influence of climate and privacy on indigenous courtyard houses in Diyarbakır, Turkey. Sci. Res. Essays 2011, 6, 908-922. [CrossRef]

45. Sayigh, A.; Marafia, H. Chapter 2-Vernacular and contemporary buildings in Qatar. Renew. Sustain. Energy Rev. 1998, 2, 25-37. [CrossRef] 
46. Al-Kolaifi, M.J. The Traditional Architecture in Qatar, Doha; The National Council for Culture, Arts \& Heritage: Doha, Qatar, 2006.

47. Gharib, R. Requalifying the Historic Centre of Doha: From Locality to Globalization. Conserv. Manag. Archaeol. Sites 2014, 16, 105-116. [CrossRef]

48. Soflaei, F.; Shokouhian, M.; Zhu, W. Socio-environmental sustainability in traditional courtyard houses of Iran and China. Renew. Sustain. Energy Rev. 2017, 69, 1147-1169. [CrossRef]

49. Harris, C.M. Dictionary of Architecture and Construction, 4th ed.; McGraw-Hill: New York, NY, USA, 2006.

50. PEO. Old Houses in Al-Asmakh Area البيوت القديمة في منطقة الأصمخ; Private Engineering Office: Doha, Qatar, 2015.

51. Jaidah, I.M.; Bourennane, M. The History of Qätari Architecture from 1800 to 1950, 1st ed.; Skira Editore: Milan, Italy, 2009.

52. Hicks, E. The gendered household: Making space for women in the study of Islamic archaeology in Qatar (poster). In Proceedings of the Seminar for Arabian Studies, British Museum; British Museum, London, UK, 3-5 August 2019.

53. Rapoport, A. The Nature of the Courtyard House: A Conceptual Analysis. Tradit. Dwell. Settl. Rev. 2007, 18, $57-72$.

54. Rapoport, A. Systems of Activities and Systems of Settings. In Domestic Architecture and the Use of Space: An Interdisciplinary Cross-Cultural Study; Cambridge Univeristy Press: Cambridge, UK, 1997; pp. 9-20.

55. Furlan, R. The Spatial Form of Houses Built by Italian Migrantsin Post World War II Brisbane, Australia. Archit. Res. 2015, 5, 31-51. [CrossRef]

56. Relph, E. Place and Placelessness; Pion: London, UK, 1976.

57. Seamon, D.; Sowers, J. Place and Placelessness, Edward Relph. In Key Texts in Human Geography; Hubbard, P., Kitchen, R., Vallentine, G., Eds.; Sage: London, UK, 2008; pp. 43-51.

58. Creswell, J.W. Research Design: Qualitative, Quantitative and Mixed Methods Approaches; Sage Publications: Thousand Oaks, CA, USA, 2003; Volume 2.

59. Newman, L. Basics of Social Research, 2nd ed.; Pearson: Boston, MA, USA, 2007.

60. Zeisel, J. Inquiry by Design: Tools for Environment-Behaviour Research; Cambridge University Press: Cambridge, UK, 1984.

61. Alitajer, S.; Molavi Nojoumi, G. Privacy at home: Analysis of behavioral patterns in the spatial configuration of traditional and modern houses in the city of Hamedan based on the notion of space syntax. Front. Archit. Res. 2016. [CrossRef]

62. Elsheshtawy, Y. The Emirati Sha'bī House: On Transformations, Adaptation and Modernist Imaginaries. Arab. Humanit. 2019, 11. [CrossRef]

63. Remali, A.M.; Salama, A.M.; Wiedmann, F.; Ibrahim, H.G. A chronological exploration of the evolution of housing typologies in Gulf cities. City Territ. Archit. 2016, 3, 1-15. [CrossRef]

64. Hanson, J. Decoding Homes and Houses; Cambridge University Press: Cambridge, UK, 1998.

65. Bellal, T. Understanding home cultures through syntactic analysis: The case of Berber housing. Hous. Theory Soc. 2004, 21, 111-127. [CrossRef]

66. Dawson, P.C. Space syntax analysis of Central Inuit snow houses. J. Anthropol. Archaeol. 2002, 21, 464-480. [CrossRef]

67. Dursun, P. Space Syntax in Architectural Design. In Proceedings of the 6th International Space Syntax Symposium, Istanbul, Turkey, 12-15 June 2007.

68. Hillier, B.; Hanson, J. The Social Logic of Space; Cambridge University Press: Cambridge, UK, 1984.

69. Fadli, F.; AlSaeed, M. A holistic overview of Qatar's (Built) cultural heritage; Towards an integrated sustainable conservation strategy. Sustainability 2019, 11, 2277. [CrossRef]

70. Terlinden, U. City and Gender: International Discourse on Gender, Urbanism and Architecture; Leske + Budrich: Opladen, Germany, 2003; ISBN 978-3-322-97563-8.

71. Hillier, B. Space Is the Machine: A Configurational Theory of Architecture; Cambridge University Press: Cambridge, UK, 1996.

72. Major, M. The Syntax of City Space: American Urban Grids; Routledge: New York, NY, USA, 2018.

73. Benedikt, M. To Take Hold of Space: Isovists and Isovists Fields. Environ. Plan. B Plan. Des. 1979, 6, 47-66. [CrossRef] 
74. Hillier, B.; Hanson, J.; Graham, H. Ideas are in things: An application of the space syntax method to discovering house genotypes. Environ. Plan. B Plan. Des. 1987, 14, 363-385. [CrossRef]

75. Hillier, B.; Penn, A.; Hanson, J.; Grajewski, T.; Xu, J. Natural Movement: Or, Configuration and Attraction in Urban Pedestrian Movement. Environ. Plan. B Plan. Des. 1993, 20, 29-66. [CrossRef]

76. Penn, A.; Hillier, B.; Banister, D.; Xu, J. Configurational Modeling of Urban Movement Networks. Environ. Plan. B Plan. Des. 1998, 25, 59-84. [CrossRef]

77. Turner, A.; Doxa, M.; O'Sullivan, D.; Penn, A. From Isovists to Visibility Graphs: A Methodology for the Analysis of Architectural Space. Environ. Plan. B Plan. Des. 2001, 28, 103-121. [CrossRef]

(C) 2020 by the authors. Licensee MDPI, Basel, Switzerland. This article is an open access article distributed under the terms and conditions of the Creative Commons Attribution (CC BY) license (http://creativecommons.org/licenses/by/4.0/). 